\title{
AP relationship of the maxillary central incisors to the forehead in adult white males
}

\author{
Maggie S. Adams \\ West Virginia University
}

Follow this and additional works at: https://researchrepository.wvu.edu/etd

\section{Recommended Citation}

Adams, Maggie S., "AP relationship of the maxillary central incisors to the forehead in adult white males" (2011). Graduate Theses, Dissertations, and Problem Reports. 3268.

https://researchrepository.wvu.edu/etd/3268

This Thesis is protected by copyright and/or related rights. It has been brought to you by the The Research Repository @ WVU with permission from the rights-holder(s). You are free to use this Thesis in any way that is permitted by the copyright and related rights legislation that applies to your use. For other uses you must obtain permission from the rights-holder(s) directly, unless additional rights are indicated by a Creative Commons license in the record and/ or on the work itself. This Thesis has been accepted for inclusion in WVU Graduate Theses, Dissertations, and Problem Reports collection by an authorized administrator of The Research Repository @ WVU. For more information, please contact researchrepository@mail.wvu.edu. 


\title{
AP RELATIONSHIP OF THE MAXILLARY CENTRAL INCISORS TO THE FOREHEAD IN ADULT WHITE MALES
}

\author{
Maggie S. Adams, DDS
}

\section{A THESIS}

\author{
Submitted to: \\ The School of Dentistry at \\ West Virginia University \\ in partial fulfillment of the requirements \\ for the degree of \\ Master of Science \\ In \\ Orthodontics \\ Peter Ngan, D.M.D., Chair \\ Chris Martin, D.D.S., M.S. \\ Thomas Razmus, D.D.S., M.S. \\ Department of Orthodontics
}

Morgantown, WV

2011 


\title{
ABSTRACT \\ AP Relationship of the Maxillary Central Incisors to the Forehead in Adult White Males
}

\author{
Maggie S. Adams, D.D.S., Peter Ngan, D.M.D., Chris Martin, D.D.S., M.S., \\ Thomas Razmus, D.D.S., M.S.,
}

Objectives: To evaluate and compare the anteroposterior relationship of the maxillary central incisors to the forehead in adult white males with harmonious profiles and in adult white male orthodontic patients. Methods: One hundred and one photographic images of adult white males with good facial harmony (control sample) were compared with 97 photographs of adult white males seeking orthodontic treatment (study sample). All images were of the face in profile with the maxillary central incisors and the forehead in full view. The images were imported into Adobe Photoshop ${ }^{\mathrm{TM}}$ and resized and rotated to the upright head position. Reference lines were constructed to assess the anteroposterior positions of the maxillary central incisors as well as forehead inclinations. Results: In the control sample, 91\% had maxillary central incisors positioned between the FFA point and glabella, $8 \%$ posterior to the FFA point, and $<1 \%$ anterior to glabella. In the study sample, 34\% had maxillary central incisors positioned between the FFA point and glabella, 59\% posterior to the FFA point, and 7\% anterior to glabella. The difference between the means for the anteroposterior maxillary incisor position were statistically significant $(\mathrm{P}=0.0001)$. The positions of the maxillary central incisors were poorly correlated with the forehead inclination in the control, but not in the study group $\left(r^{2}=0.37\right.$ and $r^{2}=0.53$ respectively). Conclusion: The forehead is an important landmark for anteroposterior maxillary incisor positioning for adult white male patients seeking improved facial harmony. 


\section{DEDICATION}

To my husband, Jeremy Adams, for always supporting me and for all the sacrifices you have made. Thank you for being patient with me on this 11 year journey as I followed my dreams of becoming an orthodontist. I am looking forward to a lifetime of journeys with you. You are the love of my life and the best husband a girl could ask for. I am so lucky to have you in my life. I love you more than you will ever know.

To my father, Hank Sammons, thank you for teaching me the importance of hard work and integrity. It has been a joy following in your footsteps. Thank you for believing in me when I forgot how to believe in myself. Thank you for pushing me to be the best person I can be. For everything thing that you have done for me and continue to do for me I cannot thank you enough. I love you dad.

To my mother, Elizabeth Sammons, thank you for teaching me the importance of enjoying life and giving to others. I couldn't ask for a better mother and best friend. Thank you for seeing the best in me even when I made it difficult. Thank you for reminding me to be compassionate and understanding when my stubbornness gets in my way. Thank you for loving me for who I am. I love you mom.

To my brother, Drew Sammons, thank you for always keeping life fun and for teaching me the importance of patience (although you definitely pushed the limits...hahaha). Thank you for teaching me how to draw imaginary lines down the middle of the back seat of the car and for showing me just how far mom and dad's buttons can be pushed until they explode. I couldn't have asked for a better brother and I cannot tell you how proud I am of the young man you have become. I love you Drew.

To some of my other family members that mean so much to me, Grandaddy Fred, Grandmother Jo, Aunt Martha, Aimee, Paul, Meghan, Zachary, Christopher, Kristin, Karson and Hannah, I love you all. You have each made a lasting impact on my life.

To my loved ones that are no longer with me on this beautiful earth but are up above watching over me each and every day, Grandaddy Jiggs and Mommom, I love and miss you both very much.

And last but not least, thank you God for all that you have blessed me with. Thank you for leading me through this wonderful journey called life. 


\section{ACKNOWLEDGEMENTS}

Dr. Peter Ngan- For believing in me and giving me a chance to live my dream. For passing your life and educational knowledge on to me and for your help with my research. For making this program the best program in the universe.

Dr. Chris Martin- For your infectious smile and jokes. For all of your help in the clinic and for always making it enjoyable. For teaching me how important it is to rinse with Listerine at least 8 times a day and for serving on my thesis committee. I'm going to miss you so much and I hope to one day succeed you as President. P.S. "I smell burnt lint!"

Dr. Thomas Razmus- For your help as a member of my thesis committee.

Dr. Tim Tremont-For exposing me to the Six Elements of Orofacial Harmony. I can never thank you enough for the countless hours you have spent teaching me over the past 3 years. You have a gift for teaching which has been both a blessing to me and this program.

Dr. Ned McFarland-For working so effortlessly at the last minute to help me with my thesis and for all your knowledge and skill you have shared with me over the past 3 years.

Part time faculty Michael Hazey, Jeff Gilmore, Thomas Jarrett, Dan Foley, Kerry Kirsch, Glenn Boyles, Rajia Sebahhi- For your knowledge and patience in the clinic. Thank you for every road trip you took to be here to make me a better student and clinician. The time I spent with each of you is invaluable.

Staff Carrie, Hillary, Joyce, Karen, Leona, and Marsha- For helping me in the clinic but most of all for being good friends and listening to me vent whenever this place was stressing me out.

Julie Wolford- For being a great friend and a great "Aunt” to my puppies. Thank you so much for walking my girls every day at lunch for me. I know they will miss you as much as I will.

Dr. Erica Reed- For being a great listener and friend. For sharing in the good, the bad, and the ugly with me.

Dr. Robert VanLaecken- For always making me smile and laugh (except when you trash my desk...hahaha). For being a great friend and always keeping it real with me. For the mental list of dance moves I now know and for the memories that literally make me laugh out loud when I think of them. You are like a second brother to me and I cannot tell you how much I am going to miss being around you every single day.

Dr. Holly Eppard- For being a great friend and confidant. I can only wish that we had become friends sooner. For being a great listener and not being afraid to tell me when I was doing 
something wrong. Oh yeah and for teaching me that I should never eat pizza at 2am after a night of good times with you!

Fellow residents Ronnie Sparks, Jung Mee Kim, Do Young Choi, Alice Wang, and Chad Westfall, as well as former residents Michael Munn, Dean Heinrichs, Kolin Weaver, Rajia Sebbahi, Thuy Do Delatour, and Michael Becht- For all the good times and laughter. You have all made my time here extremely enjoyable and I wish you all the best. 


\section{TABLE OF CONTENTS}

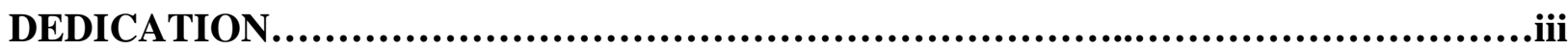

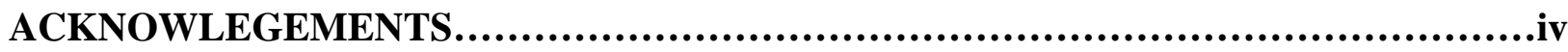

TABLE OF CONTENTS...............................................................vi

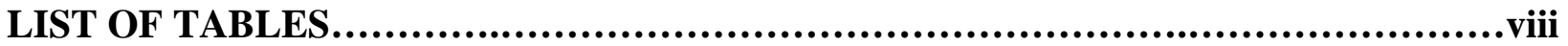

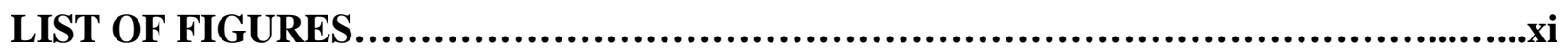

CHAPTER 1: INTRODUCTION............................................................1

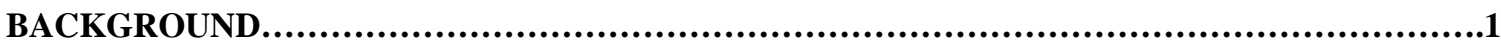

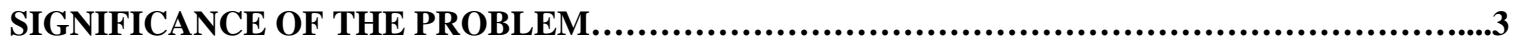

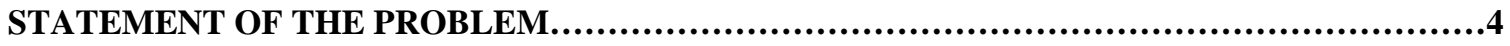

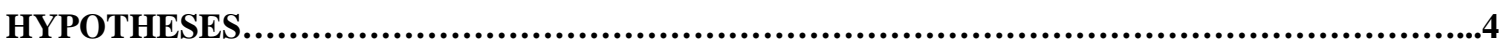

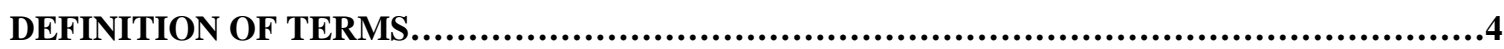

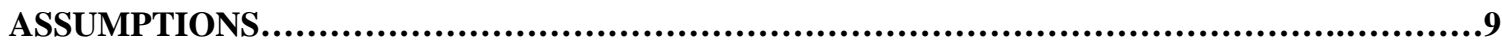

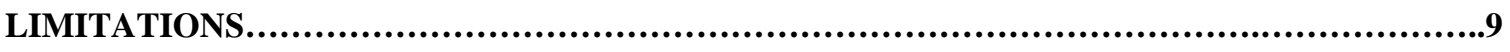

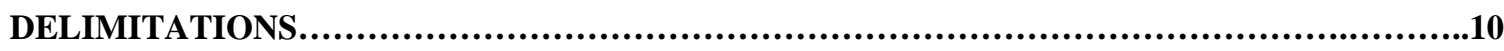

CHAPTER 2: REVIEW OF LITERATURE............................................11

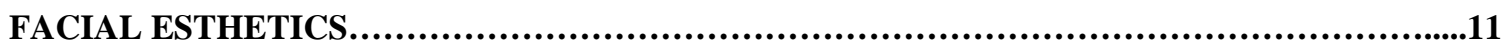

TRADITIONAL CEPHALOMETRICS......................................................14

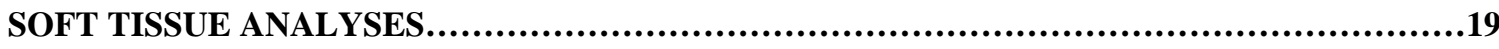

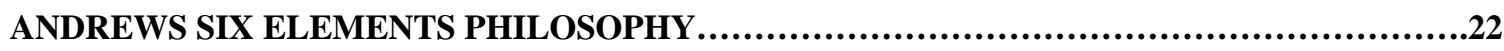

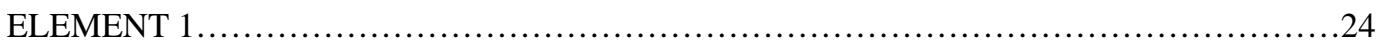

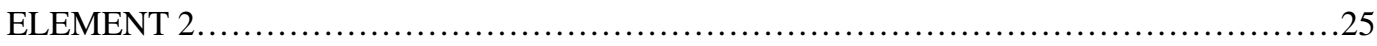

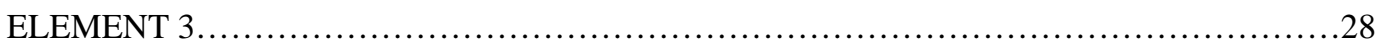

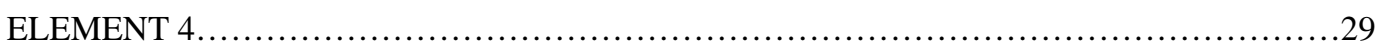

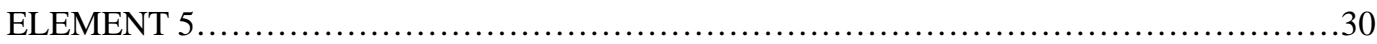


CHAPTER 3: MATERIALS AND METHODS..............................................32

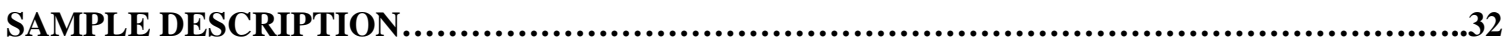

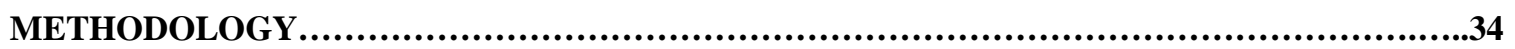

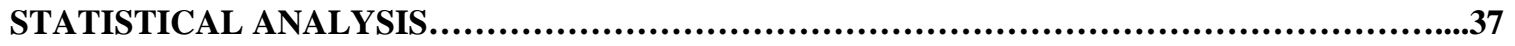

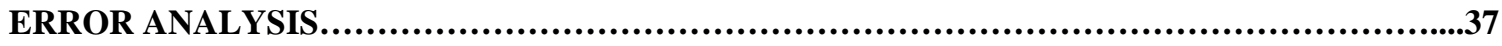

CHAPTER 4: RESULTS............................................................38

CHAPTER 5: DISCUSSION......................................................44

CHAPTER 6: SUMMARY AND CONCLUSIONS....................................46

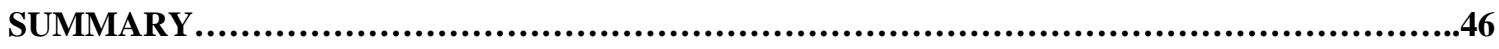

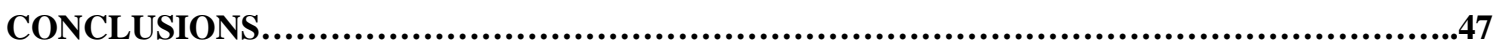

CHAPTER 7: RECOMMENDATIONS FOR FUTURE RESEARCH...................48 


\section{LIST OF TABLES}

Table 1. Measurement for Error Analysis...............................................38

Table 2. Anteroposterior Position (mm) of the Maxillary Central Incisors Relative to the Forehead's FA Point ...........................................................40

Table 3. Differences in Maxillary Central Incisor Position and Forehead Inclination Between Control and Study Samples......................................................... 40

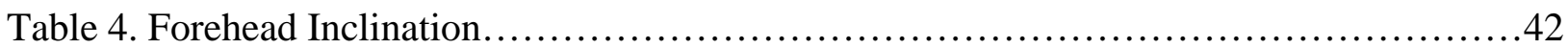




\section{LIST OF FIGURES}

Figure 1. Maxillary and mandibular teeth centered over basal bone.......................25

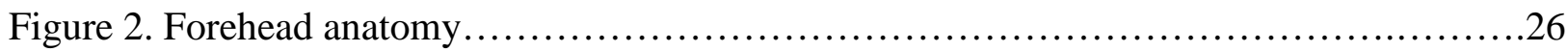

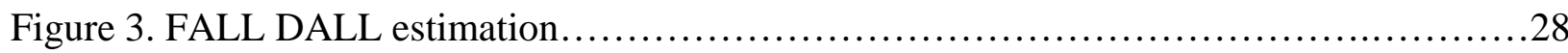

Figure 4. Forehead inclination and the effects on AP jaw positions........................29

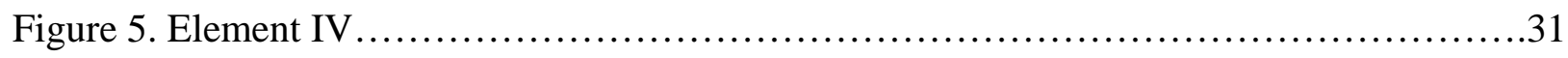

Figure 6. Example of an image used in the control sample...............................33

Figure 7. Example of an image used in the study sample................................34

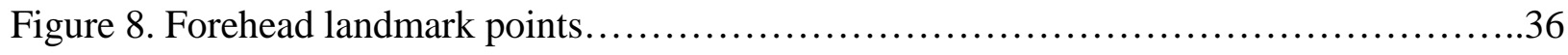

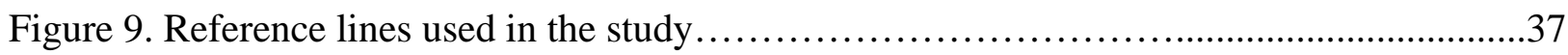

Figure 10. Measurement of error for AP relationship of the maxillary central incisors..........39

Figure 11. Measurement of error for the forehead inclination.............................40

Figure 12. Oneway analysis of maxillary central incisor position in the control and study samples.

Figure 13. Distribution of the anteroposterior maxillary central incisor positions relative to the forehead for the control sample....

Figure 14. Distribution of the anteroposterior maxillary central incisor positions relative to the

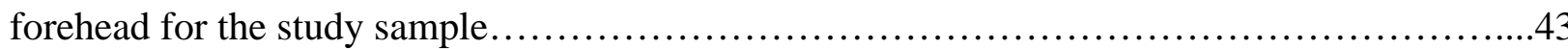

Figure 15. Change in anteroposterior maxillary central incisor position vs. change in forehead inclination for the control sample.

Figure 16. Change in anteroposterior maxillary central incisor position vs. change in forehead inclination for the study sample. 


\section{CHAPTER 1-INTRODUCTION}

With the paradigm shift in orthodontic treatment from correction of crooked teeth to treating to esthetically pleasing faces, patients often seek treatment with a goal of having their facial appearance improved. In today's society, a high value is placed on physical attractiveness. Dion et al. found that attractive individuals are believed to be more likely to get better jobs, have more successful marriages, and to experience a happier, more fulfilling life. ${ }^{1}$ Physical attractiveness extends even into the job market, with influence on job recommendations regardless of it having no relationship to job performance or responsibility. ${ }^{2}$ Berschield and Gangestad stated "the social psychological effects of physical attractiveness are pervasive, strong, and generally uniform in nature. They are such that the physically attractive, whether male or female, old or young, black or white, or of high or low socioeconomic status, receive preferential treatment in virtually every social situation examined thus far.”3 It has been recognized that overall physical appearance, more specifically facial balance and symmetry, is an indicator of how people are perceived by others in society as well as how they perceive themselves. ${ }^{4,5}$

In order to evaluate a patient's facial appearance or facial esthetics, the orthodontist must evaluate the face in profile as part of a complete orthodontic diagnosis. Over the years, many different methods for evaluating facial profiles have been studied and proposed in the orthodontic literature. Such methods include traditional cephalometrics, repose soft tissue analyses, and more recently Andrews’ Six Elements of Orofacial Harmony. Traditional cephalometrics uses internal osseous landmarks to define points, lines, and/or planes, which in turn are used to quantify anteroposterior jaw and incisor positions. The use of such landmarks, however, can be unreliable because of both errors in identification and variability in their 
positions among individuals. ${ }^{6,7}$ Also, orthodontists who treated cases to the numbers using traditional cephalometrics found that often facial esthetics suffered as a result. ${ }^{12}$ Furthermore, diagnosing and treating for facial beauty using cephalometric norms is unreliable since the hard tissue structures are not consistently related to the soft tissues of the face. ${ }^{8}$

Repose soft tissue analysis uses external soft tissue landmarks to define points, lines, and/or planes from which measurements are made and compared to norms that have previously been defined. However, as is true with traditional cephalometrics, soft tissue measurements can have large variabilities among individuals. ${ }^{12}$ Lastly, Andrews' Six Elements of Orofacial Harmony uses the forehead as a landmark for assessing the anteroposterior position of maxillary central incisors in profile. ${ }^{9}$ Andrews defined forehead landmarks and observed correlation between the forehead's prominence and inclination and the position of the maxillary central incisors in individuals with good smiling facial profiles. ${ }^{10}$ Schlosser et al found that Andrews' method of profile assessment was a "useful method to evaluate attractiveness relative to the maxillary incisor position."11

It wasn't until Dr. Will Andrews published his study on the AP relationship of the maxillary central incisors to the forehead in adult white females had anyone specifically examined the relationship between the maxillary central incisors and other external facial landmarks in profile when the incisors were displayed (smiling profile picture). Andrews reported on the AP relationship of the maxillary central incisors to the forehead in adult white females with good facial harmony as a guide for treatment planning. ${ }^{10}$ A natural follow-up to this study would be to examine the position of the maxillary central incisors to the forehead of adult white males. 
The objective of this study is to evaluate and compare the anteroposterior relationship of the maxillary central incisors to the forehead of a group of adult white male patients seeking orthodontic treatment to a control group of adult white males with good facial harmony.

\section{Significance of the problem}

Treating to traditional cephalometric numbers may have adverse effects on the face. ${ }^{12}$ Orthodontics maintains as some of its principle goals (1) Function \& Occlusion, (2) Stability, (3) Periodontium and (4) Facial and Dental Esthetics. ${ }^{13-15}$ Some may argue that many patients seek treatment not for attainment of improved function and stability, but for improved facial esthetics. Currently, emphasis is being placed on treatment planning based on facial harmony of both hard and soft tissue in a smiling profile view. As expected there is significant debate about exactly what characteristics make a face harmonious or beautiful. In the last 30 years, new diagnoses have been developed with the goal of improving facial harmony and beauty. This study will look at Lawrence F. Andrews’ Six Elements of Orofacial Harmony. This philosophy uses extracranial or external landmarks to aid in diagnosis rather than internal skeletal landmarks found in traditional cephalometrics. The Andrews' Six Elements philosophy uses the forehead as the landmark for determining the anteroposterior position of the maxillary incisor. With traditional cephalometric analyses having no universally accepted standards for facial harmony or beauty, incisor and jaw positioning is as much an art as a science. While general goals exist for the practice of orthodontics, the problem is that the specific goals may vary among orthodontists. For the diagnostic part of orthodontics to be a science, orthodontists have to agree about what constitutes optimal treatment and how to measure it. According to Dr. Lawrence F. Andrews, “This seems unlikely because every patient is different and because orthodontists do not agree about goals, landmarks or referents.”“ ${ }^{\text {If the Six Elements }}{ }^{\mathrm{TM}}$ are adopted as optimal 
standards, orthodontists will concur far more in the diagnosis of almost any given patient, the diagnostic portion of orthodontics will evolve from art to science, and patients will benefit maximally from what dentistry has to offer. ${ }^{6}$

\section{Statement of the Problem}

The purpose of this study was to evaluate and compare the anteroposterior relationship of the maxillary central incisors to the forehead in adult white males with harmonious profiles (control sample) with a random sample of adult white males seeking orthodontic treatment. (study sample).

\section{Null hypotheses}

(1)There is no significant difference in the position of the maxillary central incisors with reference to the forehead's FFA point between white male patients seeking orthodontic treatment compared to a control group of adult white male subjects with harmonious facial profiles.

(2) There is no significant difference in the correlation of the maxillary central incisors with the inclination of the forehead between adult white male patients seeking orthodontic treatment compared to a control group of white male subjects with harmonious facial profiles.

\section{Operational definitions and abbreviations}

Anatomical forehead - the exposed skin from the hairline (or where the hairline once was) to glabella

Basal bone - the bone that supports the alveolar process. Clinically it is different from alveolarprocess bone in that it does not atrophy after teeth are extracted 
Centric relation (CR)- the uppermost position of the condyle in the fossa.

Clinical forehead - the portion of the forehead that is oriented more with the face than the scalp. For straight foreheads, it is between trichion and glabella. For rounded or angular foreheads, it is between superion and glabella.

Columnella (Cm)- the most inferior and anterior point of the nose

DALL - dentition's anterior-limit line - a line that parallels the head's frontal plane and passes through the maxillary incisor's facial axis (FA) point.

Diagnosis - definition of the patient’s problem

Element I maxillary incisor- the roots of the incisors are centered over the buccolingual borders of the basal bone, crowns inclined so they can interface correctly.

Element II - for the purpose of this study, the position of the maxilla and mandible where the FA point of the Element I maxillary incisor touches the GALL and the incisors are coupled in their Key I positions..

Facial beauty - the attractiveness of a face.

Facial harmony - when the external facial features that are indirectly within dentistry's milieu are as balanced as they can be.

FA point - incisor facial axis point - a point on the midsagittal plane of the face of the clinical crown midway between its gingival and occlusal borders.

FALL - forehead's anterior-limit line - a line that parallels the head's frontal plane and passes through the forehead's FA point. 
FALL DALL - the difference between the FALL line and DALL line measured in millimeters expressed as red, green, or black. Red means the DALL is more anterior than the FALL. Green means the DALL and the FALL are on the same plane. Black means that the DALL is behind the FALL.

FFA point - forehead facial axis point - a point on the midsagittal plane of the forehead that is midway between the superior and inferior borders of the clinical forehead

Frankfort horizontal plane- a line drawn from orbitale to porion

GALL - Goal Anterior Limit Line - a line that parallels the head's frontal plane and represents the optimal anterior border for an Element I dentition. It passes through the FFA point when the cant of the forehead is 7 degrees or less. For every degree the forehead is canted more than 7 degrees, it passes through a point on the forehead that is .6 mm anterior to the FFA point, but never beyond glabella unless the patient demands it.

Glabella - the area on the frontal bone above the nasion and between the eyebrows. In profile its most prominent portion is considered the inferior border of the clinical forehead.

Gnathion (Gn)- the lowest point in the lower border of the mandible in the median plane

Gonion - the most inferior point on the angle of the mandibular body

Holdaway line (H)- a line drawn from labial superior to pogonion

Inclination - the faciolingual cant of the facial axis of the maxillary clinical crown when measured from a line perpendicular to the occlusal plane. Inclination is positive when the occlusal portion of the facial axis is facial to its gingival portion, negative when lingual. 
Key I - Interarch relationships - seven parts:

1. the mesiobuccal cusp of the maxillary first molar occludes in the mesial buccal groove of the mandibular first molar.

2. the distal marginal ridge of the maxillary first molar occludes on the mesial marginal ridge of the mandibular first molar.

3. the mesiolingual cusp of the maxillary first molar occludes in the mandibular first molar's central fossa.

4. the maxillary premolar buccal cusps rest in the embrasures of the mandibular premolars.

5. the maxillary premolar lingual cusps rest in the fosse of the mandibular premolars.

6. the maxillary canine rests in the embrasure of the mandibular canine and first premolar with the tip of its cusp slightly mesial to the embrasure.

7. the maxillary incisors overlap the mandibular incisors and the midlines of the arches match ${ }^{16}$.

Labial inferior (Li)- the point that indicates the mucocutaneous limit of the lower lip

Labial superior (Ls)- the point that indicates the mucocutaneous limit of the upper lip

Nasion (N) - the anterior point of the intersection between the nasal and frontal bones.

Natural head position (NHP) - a standardized and reproducible orientation of the head in space when focusing on a distal point at eye level ${ }^{17}$.

Mandibular plane angle- the angle formed by the intersection of a line from gonion to menton and Frankfort horizontal plane. 
Menton (Me) - the most inferior point of the anterior mandible. Soft tissue menton is defined as the most inferior point on the soft tissue chin.

Orbitale (O)- the lowest point on the inferior edge of the orbit

Porion (Po)- the central point on the upper margin of the external auditory meatus

Pogonion (Pg)- the most anterior point of the chin

Pronasale (Prn)- the most prominent point of the tip of the nose

Sella (S)- a depression on the upper surface of the sphenoid bone, lodging the pituitary gland.

Station superior (Sts)- the most inferior point of the upper lip

Stomion inferion (Sti)- the most superior point of the lower lip

Subnasale (Sn)- the point where the upper lip joins columnella

Superion - the point on angular and rounded foreheads that, in profile, represents the superior boundary of the clinical forehead, that portion of the forehead that is related more to the face than to the scalp ${ }^{18}$.

Treatment - execution of the treatment plan

Treatment planning - planning changes needed to eliminate the problems based on the diagnosis

Trichion - The superior border of the anatomical forehead. Anantomically it is a line on the forehead that is, or once was, the hairline. If the hairline has receded, it can be identified by 
having the patient raise their eyebrows and note the line of demarcation between the smooth skin of the scalp and the furrowed skin of the forehead ${ }^{18}$.

WALA ridge -a band of soft tissue immediately superior to the muccogingival junction in the mandible. $^{19}$

Will's Plane - a vertical plane running through the Element I mandibular incisor's FA point perpendicular to the occlusal plane ${ }^{18}$.

Y-axis- the angle formed by the intersection of a line from sella to gnathion and Frankfort horizontal plane.

\section{$\underline{\text { Assumptions }}$}

Several assumptions existed in order to perform this study. They were as follows:

1. Every person can perceive facial beauty and harmony.

2. People seeking orthodontic treatment may have facial beauty, but probably don't have facial harmony

3. Pictures of white males in the mass media that convey the entertainment industry are chosen because they are perceived by society to possess facial beauty and harmony.

\section{$\underline{\text { Limitations }}$}

1. Personal preferences for characteristics contributing to facial beauty and harmony may be biased by the mass media's selection of adult white male models for their publications.

2. Approximating the control sample photographs to life size can introduce some variability. 


\section{$\underline{\text { Delimitations }}$}

1) A panel of three judges was used to evaluate the control sample. If two or more of the judges did not think that the smiling profile picture exhibited good facial harmony that subject was excluded from the study.

2) The distance from trichion to incision on the lateral cephalograms of 10 adult white males was averaged and then a ruler was used to the $0.5 \mathrm{~mm}$ to approximate the same distance on the photographs when adjusting them to life size. 


\section{CHAPTER 2-LITERATURE REVIEW}

\section{Facial Esthetics}

Perhaps some of the greatest words ever written in any orthodontic text are the following quotes from Edward H. Angle. "The study of orthodontia is indissolubly connected with that of art as related to the human face. The mouth is a most potent factor in making or marring the beauty and character of the face..." "Our duties as orthodontists force upon us great responsibilities, and there is nothing in which the student of orthodontia should be more keenly interested than in art generally, and especially in its relation to the human face, for each of his efforts, whether he realizes it or not, makes for beauty or ugliness; for harmony or inharmony; for perfection or deformity of the face. Hence it should be one of his life studies.” In other words, facial esthetics has been an important issue in orthodontics for many years and continues to be to the present day.

In today’s society, a high value is placed on physical attractiveness. Television, movies, advertising, and all other forms of mass media have presented to the public faces that are generally thought of as "good looking" or beautiful. The impact of these media has been so widespread that individuals of varying ethnic and racial groups who ordinarily would be expected to develop their own concepts of facial harmony accept the "Hollywood standard" of facial excellence. ${ }^{20}$

According to Burstone, ${ }^{20}$ "In man, the lower face serves not only in the interests of digestion, speech, and respiration, but it also influences to a large extent the social acceptance and psychological well-being of the individual." “Appearance, therefore, is one of the primary functions of the face." The teeth and jaws form a dentoskeletal framework upon which lie the 
soft tissues of the face. Orthodontic treatment by altering the dentoskeletal framework may produce desirable or undesirable alterations to the soft tissues of the face. The amount of variation possible without destruction of profile esthetics has no definitive answer, for it depends upon the critical nature of the observer. ${ }^{20}$ Excellent faces, therefore, are not all identical even if it is assumed that their component parts border on statistical norms. The optimal goal of the orthodontist might then be considered the achievement of the facial harmony along with a perfect functional occlusion within the limitations of therapy.

It has been recognized that overall physical appearance, more specifically facial balance and symmetry, is an indicator of how people are perceived by others in society as well as how they perceive themselves. ${ }^{3,8}$ Evidence would suggest that people with attractive faces are likely to be regarded as more competent, likeable and in a broad sense "better" than those who are not considered facially attractive. ${ }^{8,21}$ Dion et al. found that attractive individuals are believed to be more likely to get better jobs, have more successful marriages, and to experience a happier, more fulfilling life. ${ }^{22}$ Physical attractiveness extends even into the job market, with influence on job recommendations regardless of it having no relationship to job performance or responsibility.. Berschield and Gangestad stated "the social psychological effects of physical attractiveness are pervasive, strong, and generally uniform in nature. They are such that the physically attractive, whether male or female, old or young, black or white, or of high or low socioeconomic status, receive preferential treatment in virtually every social situation examined thus far.”

There seems to be no exact rules governing why a face is beautiful. Professionals and artists alike have attempted to define and recreate an ideal. Although beauty may be easily recognized, objective standards useful to clinical practice are difficult to define. Perception of

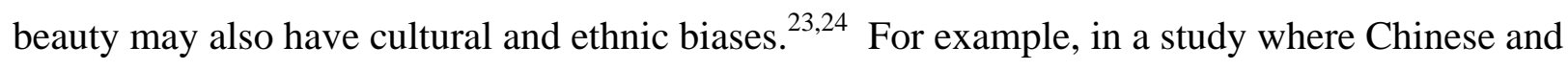


U.S orthodontists ranked facial attractiveness of Chinese and Caucasian patients, the pairs of Chinese orthodontists agreed with each other slighter better on average when ranking Chinese patients and the pairs of U.S. orthodontists agreed with each other slightly better on average when ranking white American patients. ${ }^{25}$ Furthermore, the U.S. orthodontists ranked the Caucasians as more facially attractive and the Chinese orthodontists ranked the Chinese patients as more attractive. ${ }^{25}$

Researchers from many disciplines have studied and continue to study the various aspects of facial attractiveness. Yet, with all the research on facial beauty and harmony, we still have no universal standards. There are many who believe that the standard for a harmonious face as well as facial beauty is determined by the golden proportion. The first known calculation of the golden proportion as a decimal was given by Maestlin in a letter to his former pupil, Kepler. ${ }^{26}$ This golden proportion of 1: 1.618 has been found throughout history in art, architecture, fashion, flowers, birds, and the human body. There have been many attempts to correlate ideal facial proportions with the golden proportion. ${ }^{26}$ However, in a 3-dimensional study analyzing the faces of professional models, the authors found that they did not fit the golden proportion and, interestingly, that they had various malocclusions and a wide range of cephalometric values. ${ }^{27}$ In another study of the esthetic improvement of patients having orthognathic surgery, the authors found that, whereas most subjects were considered more attractive after treatment than before, the proportions were equally likely to move away from or toward the golden proportion. ${ }^{28}$ Therefore, more research evidence is required to substantiate the true significance of this fascinating concept in the clinical assessment of facial esthetics.

Orthodontists routinely assess facial esthetics from both the frontal and profile views. Although a person's ability to recognize beauty appears to be innate, the translation of this into 
treatment goals is difficult. ${ }^{29}$ Treatment goals are even more challenged by professional bias and patient bias and desires. ${ }^{30}$ If there is a skeletal discrepancy the orthodontist determines if surgery may be indicated. Luckily, surgical advances now allow us to place the jaws precisely where we want them to improve facial attractiveness as well as function. However, the exact position where the jaws should be positioned to be the most attractive is still unknown, although many philosophies exist stating that they know exactly where the jaws belong within the facial skeleton. The Andrews' Six Elements of Orofacial Harmony philosophy currently has one of the most detailed descriptions of jaw placement for optimal facial esthetics. This philosophy will be discussed in greater detail later.

Currently there are many techniques and philosophies that orthodontists use to evaluate a patient's facial attractiveness, including traditional cephalometric analyses, soft tissue analysis and The Six Keys to Orofacial Harmony. Over 250 cephalometric analyses currently exist providing a multitude of normative values. In recent years more emphasis has been placed on using the facial soft tissue for diagnostic data to assist in treatment planning - the so called "soft tissue paradigm.,31,32 An optimal goal would be to have the teeth in a gnathological occlusion and esthetic alignment while also having the teeth and jaws in a position to provide an esthetic face.

\section{Traditional Cephalometrics for Assessing Facial Esthetics}

As a standard, lateral cephalometric headfilms have been used to diagnose, treatment plan, and predict hard and soft tissue responses to orthodontic treatment. ${ }^{4}$ Over the years multiple cephalometric analyses have been developed in an attempt to qualitate and quantitate esthetic facial profiles. Each analysis has different planes, lines, referents, landmarks, and angles to use to diagnose skeletal and dental malocclusions. Particularly important, cephalometric 
normative values have been identified that guide diagnosis and tooth movement decisions. The cephalometric analysis has been used as the standard because of the ease of procuring, measuring, and comparing hard tissue structures and the belief that treating to cephalometric hard tissue norms results in a pleasing faces. ${ }^{4}$ Some of the more common cephalometric analyses include Rickets, Downs, Steiner, Wits and Tweed, although there are many more that could be listed.

The Rickett's ${ }^{33}$ analysis of the lateral headfilm includes four main categories: (1)the chin in space, (2)convexity, (3)teeth, and (4)profile. To evaluate the chin in space Rickett's used the facial axis which is the angle formed between the B-N plane and the plane from foramen rotundum (PT) to Gn, the facial angle which is the angle between the facial plane (N-Pg) and $\mathrm{FH}$, and the mandibular plane which is the angle formed between Go-Me and FH. The convexity of the middle face is measured from point A to the facial plane. To evaluate where the teeth should be located within the jaws Rickett's used the denture plane which is a line from A-Pg to measure the position of the anterior teeth, the upper molar to pterygoid vertical (PtV) which is the back of the maxilla to the distal of the upper molar to determine whether the malocclusion is due to the position of the upper molar, and the lower incisor inclinations which is the angle between the long axis of the lower incisor and the A-Pg plane to determine the procumbancy of the lower incisors. Lastly, he used the lower lip to E-plane which is the distance between the lower lip and the esthetic (nose-chin) plane.

When observing facial profiles, WB Downs ${ }^{34}$ noted that generally the position of the mandible could be used in determining whether or not faces were balanced. According to Downs, the "ideal" profile, which represents the best harmony is when the position of the

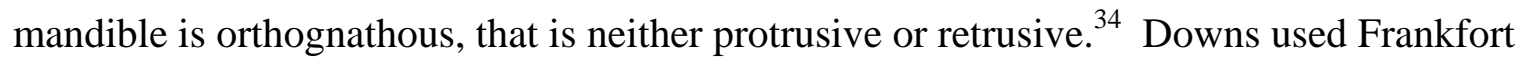


horizontal plane as a reference base. His measurements included the facial angle (a line from NPg to $\mathrm{FH}$ ) to measure the degree of retrusion or protrusion of the lower jaw; the angle of convexity ( a line from N-Point A to point A-Pg) to measure the degree of the maxillary basal arch at its anterior limit relative to the total facial profile; A-B plane to measure the relation of the anterior limit of the apical bases to each other relative to the facial line; mandibular plane angle (a line from Go-Me to FH) ; and lastly Y-axis ( a line from S-Gn to FH) to measure the degree of downward, rearward, or forward position of the chin in relation to the upper face.

Steiner's analysis uses a different reference line than Down's. Steiner uses the anterior cranial base (sella to nasion) as the line of reference instead of Frankfort's horizontal because he felt that porion and orbitale are not always easily identified on lateral cephalometric headfilms. ${ }^{35}$ Steiner's measurements include SNA angle (sella to nasion to point A) which relates the position of the maxilla to the cranial base; SNB angle (sella to nasion to point $\mathrm{B}$ ) which relates the mandible to the cranial base; ANB (point A to nasion to point B) which relates the maxilla to the mandible; the angle of the occlusal plane to S-N, and the angle of the mandibular plane (Go-Me) to the anterior cranial base (S-N).

The ANB angle is the most commonly used measurement for appraising anteroposterior disharmony of the jaws. ${ }^{36}$ Although ANB is a good indication of anteroposterior jaw relationship in most instances, there are many situations in which this reading cannot be relied on. The purpose of the Wits appraisal is to identify instances in which the ANB reading does not accurately reflect the extent of anteroposterior jaw discrepancies. ${ }^{36}$ The occlusal plane is traced and then a line is drawn perpendicular to it running from nasion to point A crossing the occlusal plane and nasion to point $\mathrm{B}$ crossing the occlusal plane. Then, a millimeter ruler is used to measure the distance on the occlusal plane between the two lines that were drawn across it. The 
Wits appraisal is a linear measurement and not an analysis in itself. ${ }^{36}$ It is simply an adjunctive diagnostic aid that may prove useful in assessing the extent of anteroposterior skeletal discrepancies and it determining the reliability of the ANB angle. ${ }^{36}$

Charles H. Tweed ${ }^{37}$ devoted his professional career to the study of the anterior limits of the dentition. Synonymous with Tweed's name is the diagnostic facial triangle. Tweed's diagnostic triangle is composed of the Frankfort-mandibular plane angle (FMA), the Frankfortmandibular incisor angle (FMIA), and the incisor-mandibular plane angle (IMPA). The interrelationship of these three cephalometric angles give the diagnostician information about the patient's vertical skeletal pattern, the relationship of the mandibular incisors to the basal bone, and the relative about of protrusion, or lack thereof, of the face. ${ }^{37}$ The mean values of these three angles are 25, 68, and 87 degrees, respectively.

As one can see from the many different cephalometric analyses discussed above, traditional cephalometrics uses internal osseous landmarks to define points, lines, and/or planes, which in turn are used to quantify anteroposterior jaw and incisor positions. The use of such landmarks, however, can be unreliable for many reasons. Baumrind and Frantz ${ }^{38}$ report that the unreliability of cephalometrics is due to two general classes of error. The first may be termed “errors of projection." These result from the fact that the head film is a two-dimensional shadow of a three-dimensional object. Since the rays which produce the shadow are nonparallel and originate from a very small source, head films are always distorted enlargements, the enlargement factor varying with the plane at which the estimated point lies. Head films are further distorted by foreshortening of distances between points lying in different planes and by radial displacement of all points and structures not on the principal axis ${ }^{38}$ The second general class of errors in head film measurement may be termed "errors of identification." These are the 
errors involved in the apparently straightforward process of identifying specific anatomic landmarks on head films.

Arnett and Bergman state many other reasons for the inadequacy of cephalometrics. First, reliance on cephalometrics can lead to esthetic problems. For example, the assumption that bite correction leads to correct facial esthetics is not always true and may, in some instances, lead to less than desirable facial outcomes. ${ }^{4}$ Secondly, when the cranial base is used as the reference line to measure the facial profile, false findings can be generated. ${ }^{4}$ Michiels ${ }^{5}$ studied 27 nonorthodontic Class I patients to test the validity of various popular cephalometric measurements used to predict clinical profiles. His conclusions were that (1) measurements involving the cranial base landmarks are inaccurate in defining the actual clinical profile; (2) measurements involving intra-jaw relationships were slightly more accurate in reflecting the true profile; (3) no measurement is $100 \%$ accurate; (4) the soft tissue thickness and axial inclination of incisors are the most important variables in inaccuracy. Lastly, each cephalometric study examines different measurements as being the key to diagnosis. ${ }^{4}$ Therefore, when different cephalometric analyses are used to examine the same patient, different diagnoses, treatment plans, and results can be generated. Wylie ${ }^{39}$ analyzed 10 patients using five popular cephalometric analyses and found only $40 \%$ agreement on treatment planning. He concluded that "cephalometrics should not be the primary diagnostic tool for dentofacial diagnosis.” Wylie’s patient population had skeletal malocclusions. Perhaps cephalometrics are more reliable as a predictor of tissue changes when no skeletal disharmonies are present. Many cephalometric norms have been based on patient populations that had no skeletal disharmonies. Regardless of presence or absence of a skeletal disharmony, no single parameter in cephalometry should be relied on entirely and interpreted as absolute value. ${ }^{36}$ 
Fortunately, in more recent years orthodontic philosophies are emerging that throw cephalometric measurements to the way side. These new philosophies, such as Andrews' Six Elements of Orofacial Harmony, do not believe that if the teeth are straightened and the occlusion is corrected to cranial base norms, optimal facial esthetics will result. Unfortunately, many orthodontists still heavily rely on cephalometric analyses for treatment planning which sometimes leads to esthetic problems. Furthermore, diagnosing and treating for facial beauty using cephalometric norms is unreliable since the hard tissue structures are not consistently related to the soft tissues of the face. ${ }^{8}$ The assumption that bite correction based on cranial base standards leads to correct facial esthetics is not always true and might, in some instances, result in less than desirable facial outcomes. This is because when the cranial base is used as a reference line for measuring profile, false findings can be generated because the cranial base is as variable as the dental and facial structures that it measures. Measuring a variable to a variable leads to variable facial outcomes.

\section{$\underline{\text { Soft Tissue Analyses for Assessing Facial Esthetics }}$}

Edward H. Angle, one of the first to write about facial harmony, emphasized the importance of soft tissue. ${ }^{40}$ He considered the mouth a most potent factor in making or marring the character of the face, with the form and beauty of the mouth itself depending on the occlusal relation of the teeth. His chief concern was establishing a harmonious relationship between the mouth and other features of the face. Following Angle's lead some authors such as Downs ${ }^{34}$ began to incorporate measurements of the soft tissue facial profile into their cephalometric analyses because they were beginning to find that anomalies in hard tissues could be masked or exaggerated by soft tissues. In other words, soft tissues did not always follow the underlying 
dentoskeletal profile. Since this time many different soft tissue analyses have been created to assess the soft tissue that overlays the facial skeleton.

Many well-known names (Angle, Broadbent, Tweed, Bjork, etc...) in the orthodontic field have given their opinions concerning the relationship between the soft tissue integumental profile and the underlying skeletal structures. Not surprisingly there is no consensus, although Wylie $^{39}$ states, that there is a tendency for orthodontists and oral surgeons to rely more on the clinical impression rather than cephalometric analysis when treatment planning. In other words, while regarding cephalometrics as a convenient source of information about growth and the growth potential of the patient, orthodontists and oral surgeons tend to look at the soft tissue profile first. Furthermore, according to the research of Kuyl et al ${ }^{41}$ more significance should be attached to soft tissue profile evaluation than to cephalometric analysis in orthodontic diagnosis and treatment planning.

There are many soft tissue analyses that assess the face in profile. Some of the soft tissue analyses use the lateral headfilm to look at certain points, angles, and planes, while other analyses of the soft tissue use a clinical assessment of the soft tissue or photographic images. The esthetic plane analysis of Ricketts ${ }^{42}$ is a soft tissue cephalometric analysis based on the esthetic plane, which is a line drawn tangent to the tip of the nose and soft-tissue pogonion. According to Ricketts, a profile is considered to be ideally beautiful when the lower lip is approximately $2.0 \mathrm{~mm}$ and the upper lip is $4.0 \mathrm{~mm}$ posterior to the esthetic plane.

The nasiolabial angle analysis is an indicator of the amount of protrusion of the upper lip relative to the inferior border of the nose. On average this angle measures $74^{\circ}$. However, according to Satravaha ${ }^{43}$ the nasiolabial angle is of limited value because Burstone's 
measurements, the basis of this analysis, are not internationally accepted. For example, according to Hinds and Kent, ${ }^{44}$ the value of the nasiolabial angle should measure approximately $110^{\circ}$ or more in adult females.

Burstone $e^{20,45}$ carried out extensive esthetic analysis of the facial profile. Within the linear parameters, he defined the position of the upper (Ls) and lower (Li) lips regarding the Sn-Pg line, the nasal length (measured perpendicular to the palatine plane), the length of the upper (Sn-Sto) and lower (Sto-Me) lips, and the interlabial gap $\left(\mathrm{Sto}^{\mathrm{s}}-\mathrm{Sto}^{\mathrm{i}}\right)$. Then, Burstone along with Legan ${ }^{46}$ described the angle of convexity which is formed by soft tissue glabella, subnasle, and the soft tissue pogonion.

Holdaway ${ }^{47}$ defined H-line (Ls-Pg) with which he evaluated the subnasal position (Sn$\mathrm{H})$, and the positions of the superior labial sulcus (Sls-H), the inferior labial sulcus (Sli-H), and the inferior lip ( $\mathrm{Li}-\mathrm{H})$. He also defined the nasal prominence and the thickness of the upper lip at the level of A-point and the chin at Pg.

In 1991, Bass $^{48}$ introduced the position of the upper lip as a key for orthodontic treatment. He took the records in natural head position, using the true horizontal (TH) as a reference line. He defined the ideal position of the upper incisor, Pg, and the upper lip using a perpendicular line to $\mathrm{TH}$. He also established the exhibition of 2 to $3 \mathrm{~mm}$ of the upper incisor below the interlabial gap.

Merrifield $^{49}$ reported the Z-angle measurement and profile line to provide an accurate critical description of the relationship of the lower face. This angle is formed by the Frankfort horizontal plane and profile line, formed by a line joining the extreme point of the soft tissues of the chin and the more prominent lip, usually the upper. 
Some photographic soft tissue analyses include those of the surgeons Powell and Humphreys ${ }^{50}$ defined their esthetic triangle between the planes N-G/nasal dorsum/G-Pg/Eplane/cervical plane C-Me. In their analysis, they also defined the position of the lips, the exposure of the incisor edge at rest, and the incisor exposure at broadest smile.

Epker ${ }^{51}$ took his records in natural head position (NHP), using the true vertical (TV) as the reference line on which he defined proportional measures as the following; the upper lip (SnSto) is $30 \%$ of the inferior third of the face (Sn-Gn), the inferior lip (Sto-Sm) is $28 \%$ of the inferior third of the face, the height of the chin is $42 \%$ of the inferior third, the nasal depth (SnPrn) is $40 \%$ of the nasal length ( $\mathrm{N}-\mathrm{Sn})$.

Arnett and Bergman ${ }^{4}$ described an analysis of the soft tissue facial profile on photographic records in NHP. Their analyses of the symmetry, both vertical and horizontal, the contour of the smile line, the facial middle lines, and the facial contour were important. In their linear measurements, they analyzed the position of the upper and lower lips in relation to the SnPg line (previously used by Burstone), the length of the upper (Sn-Ls) and lower (Li-Me) lips, the upper incisor exposure at rest, and the interlabial gap.

\section{Andrews Six Elements of Orofacial Harmony}

Dr. Andrews began studying "ideal” non-treated orthodontic study models in the early 1960's looking for characteristics of occlusion that could be emulated through orthodontic treatment. ${ }^{52}$ Collecting study models from dentists and orthodontists, he discovered 120 casts of patients considered to have good to excellent occlusion. Six characteristics were found common

to all casts, which he termed the Six Keys of Optimal Occlusion. ${ }^{53}$ Although the individual keys were not entirely new, they were valuable together as a complete set of indicators of optimal 
occlusion judged from tangible landmarks. The keys include: Key I - interarch relationship, Key II - crown angulation, Key III - crown inclination, Key IV - rotations, Key V - tight contacts, Key VI - curve of spee. ${ }^{2}$ From these keys and study models as well as his past work, Andrews developed the Straight-Wire Appliance System (SWA) in 1970. ${ }^{6,53}$ The SWA is a system in which the bracket is built to a certain prescription including inclination, angulation, and prominence specific to each tooth and treatment plan, so that use of straight wires will give a treatment result similar to the optimal occlusions Andrews studied. ${ }^{6,53}$

Prior to Andrews' Six Elements of Orofacial Harmony, there was no set of guidelines for tooth and/or jaw placement based on facial harmony and beauty. His philosophy sets positional goals for the teeth and jaws, as well as landmarks and references to be used for measuring the quality of their positions. The only guidelines with widespread acceptance were the cephalometric norms. These norms were based on samples from what was considered a "normal” population of Caucasian males and females and were to serve as guidelines to a "normal" face. The studies producing the norms used various cephalometric techniques. Some used lateral repose and some had the patients with closed lips regardless of lip competence. Cephalometric norms were based on internal landmarks with a large range of positions and many orthodontists do not locate the landmarks alike on the headfilms. ${ }^{52}$ Andrews and others believed that these norms could produce varied soft tissue and esthetic outcomes.

During the 1980's Andrews began examining photos of models, actors, and other people from magazines. He felt that with society being the ultimate judge of beauty, some common characteristics may exist among the photos that could aid in orthodontic and surgical diagnosis and treatment planning. Andrews did find commonalities in the group of photos and from this began the Six Elements philosophy. ${ }^{6}$ Andrews concluded that orthodontists should consider the 
following six areas when diagnosing and treatment planning a case: 1) Arch shape and length,

2) Anterior-posterior jaw positions, 3) Buccolingual jaw widths, 4) Vertical jaw measurements,

5) Pogonion prominence, and 6) occlusion. ${ }^{6}$

The Six Elements diagnostic method uses landmarks (a point or line representing unique and positionally correct anatomy that can be used to measure the quality of the position of the teeth and jaws) and referents (a point or line that represents anatomy that may or may not be positionally correct). Use of the Six Elements diagnostic method should, according to Andrews, produce a treatment plan for each individual that is unique to their face, not based on norms, but on facial beauty and harmony. ${ }^{52}$ The Six Elements of Orofacial Harmony are "universal" meaning that they should work equally well for patients regardless of race, age, or gender. ${ }^{52}$ Dr. Andrews believes that if the Six Elements are met, the soft tissue features will be optimal and unique for each patient. The following is the diagnostic method.

\section{ELEMENT 1: ARCH SHAPE AND LENGTHS}

The goals of Element I are for the roots of maxillary and mandibular teeth to be centered over basal bone with the crowns inclined for optimal occlusion (Figure 1). The depth of the core line should be between 0 and $2.5 \mathrm{~mm}$. From the occlusal perspective, the FA points should approximate the WALA ridge within a range of .1-2.2 mm depending on the tooth. The landmark for the maxillary core line shape is dictated by the mandibular core line established by the WALA ridge. ${ }^{6}$

Element I is achieved using dental casts, photos and radiographs. The core discrepancy (CD) is first calculated by comparing the mesiodistal diameter of the corrected arch's core line to the mesiodistal diameters of all the teeth in the arch. This is basically the arch's dental crowding 
or spacing. Core line changes based on ideal placement of the teeth superior-inferiorly, anteroposteriorly, and buccolingually are summed with the core discrepancy to give the interim core discrepancy or ICD. This is the arch's total core line discrepancy with all the teeth in their Element I positions. ${ }^{6}$

Figure 1. Maxillary and Mandibular Teeth Centered Over Basal Bone (@ permission given by Lawrence and Will Andrews for use of this image)

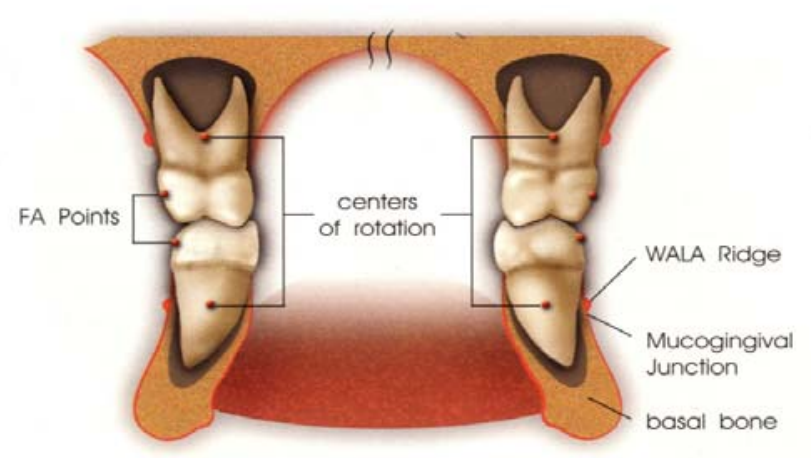

\section{ELEMENT II: AP JAW POSITIONS}

The maxilla is in its Element II position when the maxillary incisor is Element I with the FA point touching the Goal Anterior Limit Line (GALL). The mandible is Element II if it is in Key I occlusion with an Element II maxilla. To determine the Element II position of the jaws, clinical and radiographic data must be examined. The forehead is used to find the GALL for several reasons. Dr. Andrews found from his study of individuals with facial harmony that there is a correlation between the prominence and inclination of the forehead and the anterior positions of the teeth and jaws. Also, the AP relationship of the maxillary incisor to the forehead remains unchanged throughout the patient's life. First the patient's forehead is classified as round, 
straight, or angular to aid in determining the forehead's FA point (FFA). The FFA point is the midpoint of the clinical forehead. For straight foreheads, the clinical and anatomical foreheads are the same, therefore, the FFA is the midpoint between trichion and glabella. For angular and round foreheads, the clinical forehead (superion to glabella) is different from the anatomical forehead (trichion to glabella). In this case, the FFA is the midpoint between superion and glabella (Figure 2).

Figure 2: Forehead anatomy A: Straight; B: Rounded; C: Angular (@ permission given by Lawrence and Will Andrews for use of this image)

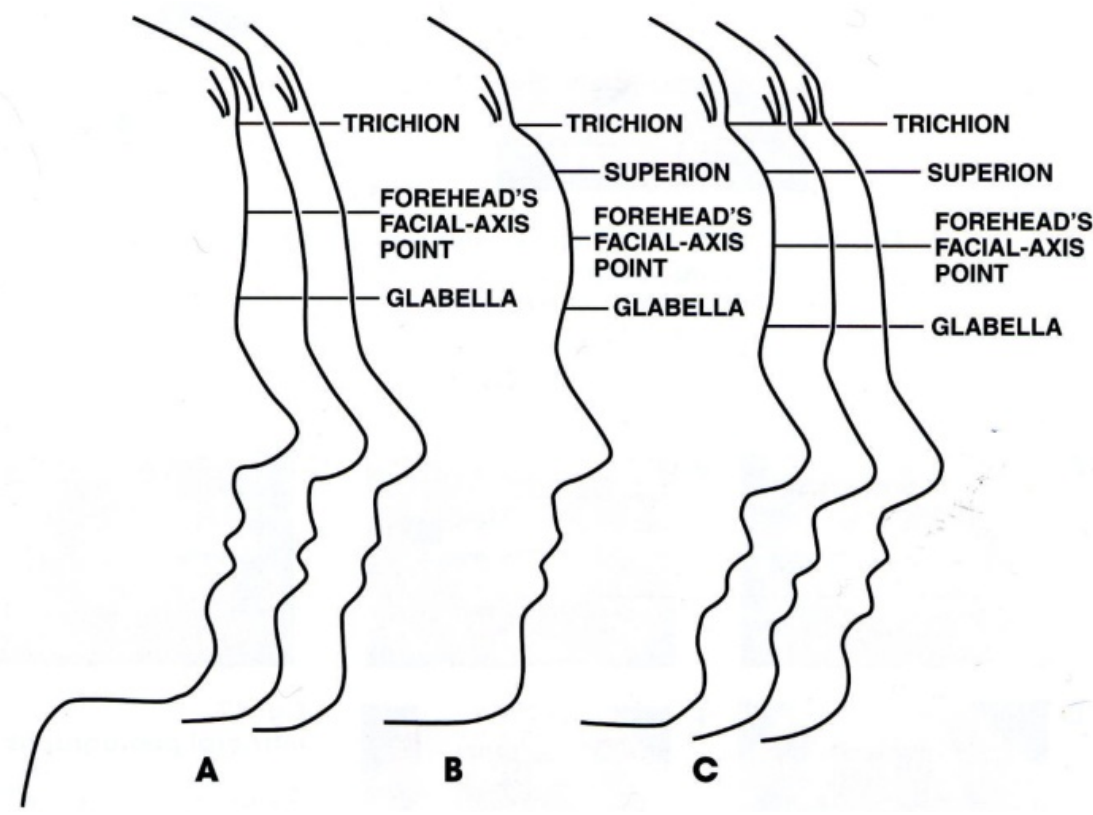

After determining the FFA point, the FALL/DALL estimation can be done. This is the distance between the FALL (the line parallel to the head's frontal plane running through the forehead's FA point) and the DALL (the line parallel to the head's frontal plane running through the maxillary incisor's FA point) (Figure 3). For this estimation, the distance between the FALL 
and DALL should be judged in millimeters and noted in the patient's chart. For example, if the DALL is $3 \mathrm{~mm}$ behind the FALL, the FALL/DALL would be expressed as $-3 \mathrm{~mm}$. If the DALL is $3 \mathrm{~mm}$ anterior to the FALL, the FALL/DALL would be expressed as $+3 \mathrm{~mm}$. The patient's clinical forehead inclination is used to determine the GALL. For every degree the forehead is canted more than 7 degrees, the GALL passes through a point on the forehead that is $0.6 \mathrm{~mm}$ anterior to the FFA point, but never beyond glabella (Figure 4). Dr. Andrews uses a specific nomenclature for expressing the jaw positions in relation to the GALL. Jaws with Element I incisors on the GALL are said to be "green." Jaws with Element I incisors behind the GALL are said to be "black" (B). Jaws with Element I incisors anterior to the GALL are said to be "red" (R). Furthermore, a millimeter measurement of the incisor's FA point to the GALL can be added. For example, a maxilla with the Element I incisor's FA point $4 \mathrm{~mm}$ posterior to the GALL is called a B4 maxilla. Using an acetate paper tracing, the maxilla and Element I incisor are positioned with the incisor's FA point on the GALL. The traced mandible with an Element I incisor are then placed in a Key I relationship. This places the maxilla and mandible in the Element II positions. If anterior or posterior movement is necessary to position the jaws in an Element II position, the same movement would be necessary surgically. The movement of the acetate template represents the surgical moves needed to place the jaws in their Element II positions. 
Figure 3: FALL DALL estimation (๔ permission given by Lawrence and Will Andrews for use of this image)

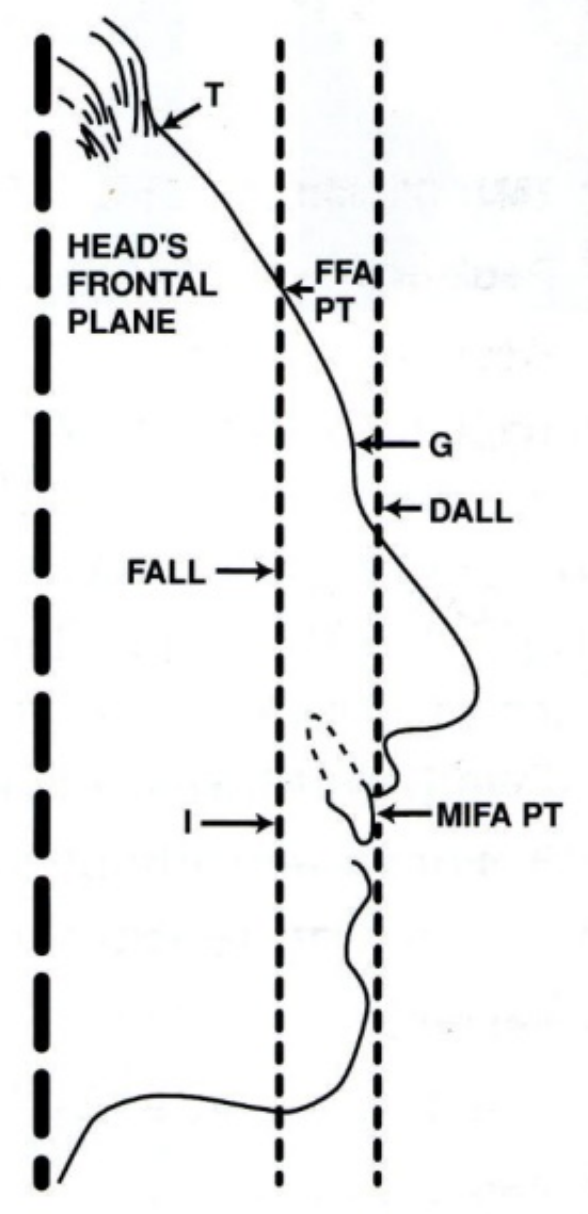


Figure 4: Forehead inclination and the effects on AP jaw positions. A: Straight forehead with inclination of 7 degrees or less, GALL passes through the FFA point. B and C: Forehead inclination of more than 7 degrees. For every degree of forehead inclination more than 7 degrees, the GALL passes through a point on the forehead $0.6 \mathrm{~mm}$ more anterior to the FFA point. The anterior limit for the GALL is glabella. (From Andrews Journal of Orthodontics and Orofacial Harmony vol. 1 no. 2, 2001). ( permission given by Lawrence and Will Andrews for use of this image)
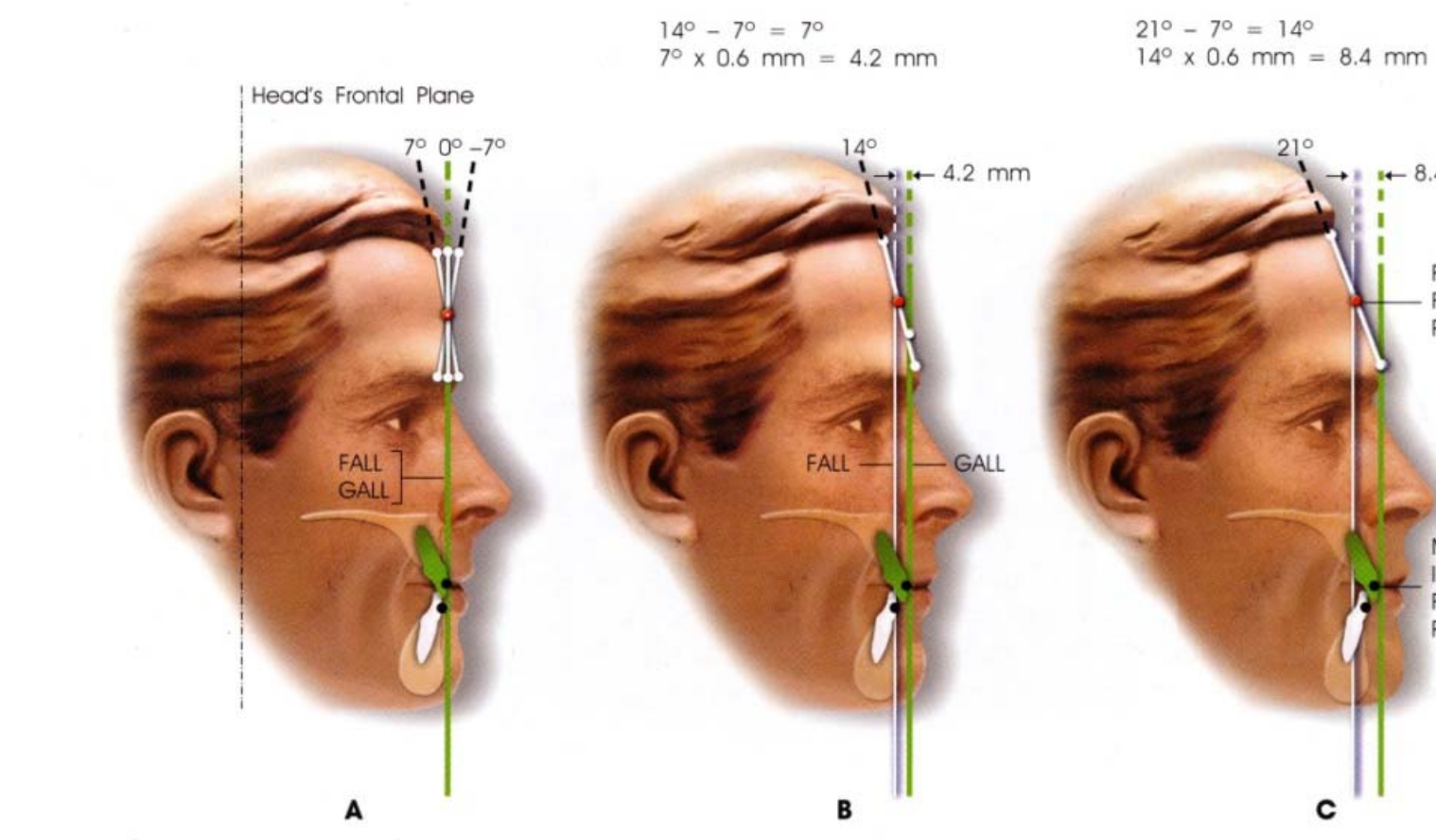

B

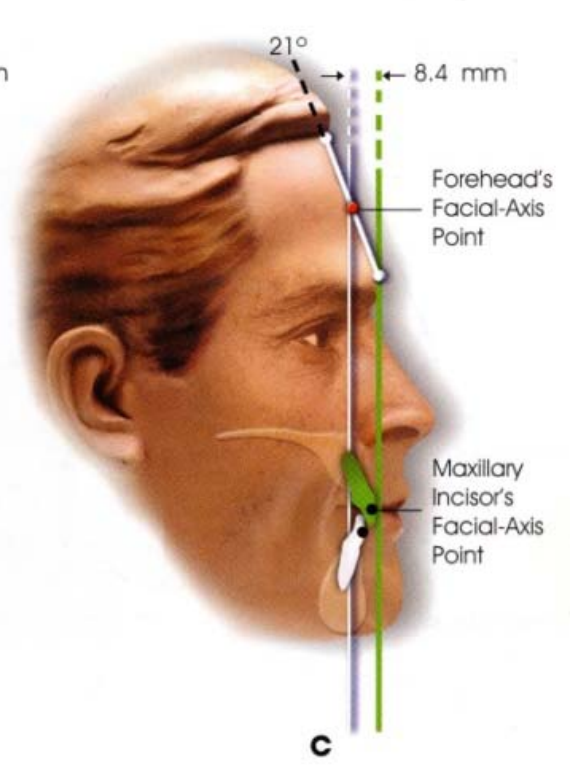

\section{ELEMENT III: BUCCOLINGUAL JAW RELATIONSHIPS}

The mandibular basal bone is naturally Element III. It will be unchanged throughout treatment. The FA points of the Element I mandibular molars serve as the landmarks for assessment of maxillary basal bone width. The maxilla is Element III when the maxillary and 
mandibular arches are Element I and the teeth are in a cusp fossa relationship buccolingually. When measuring from the FA points of the Element I teeth, the Element III maxillary arch is several millimeters wider than the Element III mandibular arch. ${ }^{52}$ Clinically this relationship is assessed from measurements on the dental casts. A buccolingual deficiency is noted as a space discrepancy when calculating the ICD and, therefore, the total space deficiency or crowding.

\section{ELEMENT IV: SUPERIOR INFERIOR JAW RELATIONSHIPS}

Element IV has been divided into four parts with specific goals and objectives for the anterior and posterior parts of the maxilla and mandible. The anterior maxilla is Element IV when the FA point of the Element I maxillary incisor is at the same level as the inferior border of the upper lip in repose. The anterior mandible is Element IV when the distance measured from the FA point of the Element I mandibular incisor to hard tissue menton is approximately half the distance from the condyle's superior surface to hard tissue gonion(Figure 5 A). For the posterior maxilla and mandible to be Element IV the distances between 1) glabella to subnasale, 2) subnasale to menton, and 3) the external auditory meatus to soft tissue gonion should all be approximately equal and there should be no posterior open bite when the anterior maxilla and mandible are Element IV and in occlusion (Figure 5 B). ${ }^{52}$ Element IV is assessed from a series of measurements made from the headfilm tracing. The vertical heights of the maxilla and mandible are controlled by movements of the acetate paper templates. The movements of the acetate templates simulate the surgical moves necessary to achieve Element IV. Not only is the maxillo-mandibular complex movable in a straight vertical direction, but the entire complex can also be rotated around the Element IV anterior maxilla altering the inclination of the occlusal plane and anterior posterior prominence of hard tissue pogonion. These are important movements to consider before planning surgical moves. Dr. Andrews feels that the ideal 
inclination of the occlusal plane is 7 degrees from the GALL if achievable while creating an Element IV vertical jaw relationship. ${ }^{6}$

Figure 5: A: For the Element IV anterior mandible, the distance from the Element I incisor FA point to hard tissue menton should be approximately half the distance from the condyle's superior surface to hard tissue gonion. B: for the Element IV posterior maxilla and mandible, the distances for a, b, and c should be approximately equal.

(From Andrews Journal of Orthodontics and Orofacial Harmony vol. 1 no. 2, 2001).

(@ permission given by Lawrence and Will Andrews for use of this image)

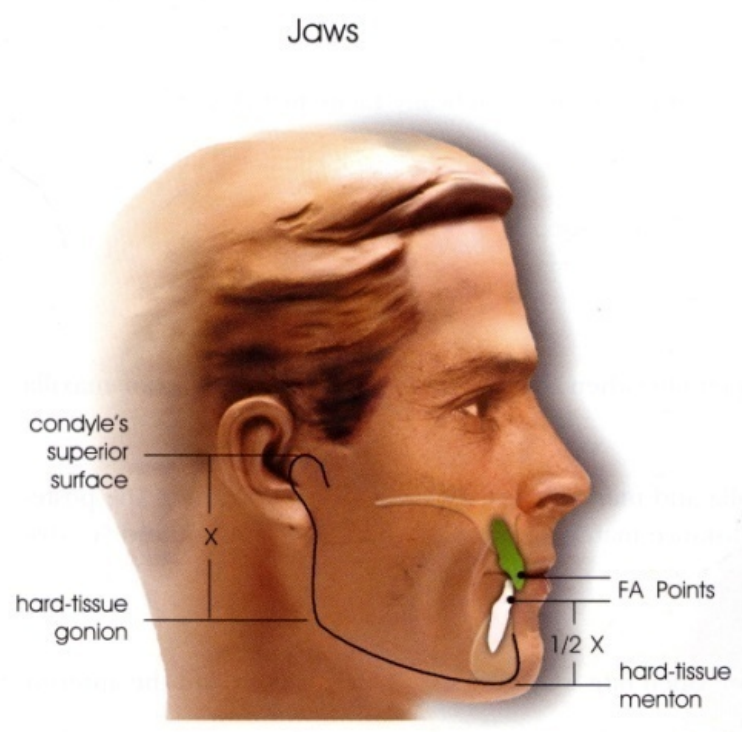

A

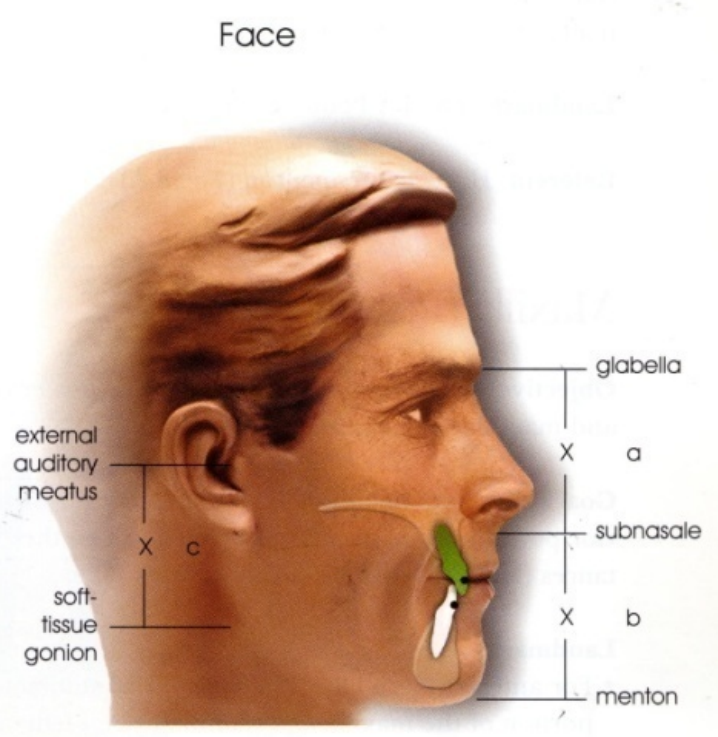

B

\section{ELEMENT V: POGONION PROMINENCE}

The prominence of hard tissue pogonion should be unique for each individual. Will's Plane is a line perpendicular to the occlusal plane passing through the FA point of the Element I 
mandibular incisor. The anteroposterior prominence of pogonion should match the anteroposterior position of Will's Plane to be Element V. The patient is described as having a B3 pogonion if its AP position is $3 \mathrm{~mm}$ posterior to Will's Plane. An R3 pogonion would be 3 mm anterior to Will's Plane. ${ }^{52}$ This is assessed from the radiographic headfilm tracing using a template.

\section{ELEMENT VI: OCCLUSION}

Element VI is achieved when the patient's occlusion meets the Six Keys to Optimal Occlusion when the condyles are in centric relation. Again, the Six Keys are: Key I - interarch relationship, Key II - crown angulation, Key III - crown inclination, Key IV - rotations, Key V - tight contacts, Key VI - curve of spee. Dr. Andrews’ study of naturally occurring good occlusions found specific relationships of correctly positioned teeth. Angulations and inclinations have a normal range and vary according to each tooth. There is also a specific pattern of occlusion with cusps being related to fossa or marginal ridges. Dental casts are needed for this assessment. ${ }^{52}$ 


\section{CHAPTER 3-MATERIALS AND METHODS}

\section{Sample Description}

\section{Control sample}

The control sample consisted of one hundred and one facial photographic images of adult white males in smiling profile collected from various internet website publications including many magazine websites. The criteria for inclusion were as follows 1) the maxillary central incisors will be fully bared and 2) the subjects have a generally pleasing appearance in profile (Figure 6). A panel of three orthodontists examined the photographs and determined whether the profile was pleasing. Two of the three evaluators had to agree that the profile was pleasing in order for it to be included, if not these photographs will not be included in the study.

Figure 6. Example of an image used in the control sample.

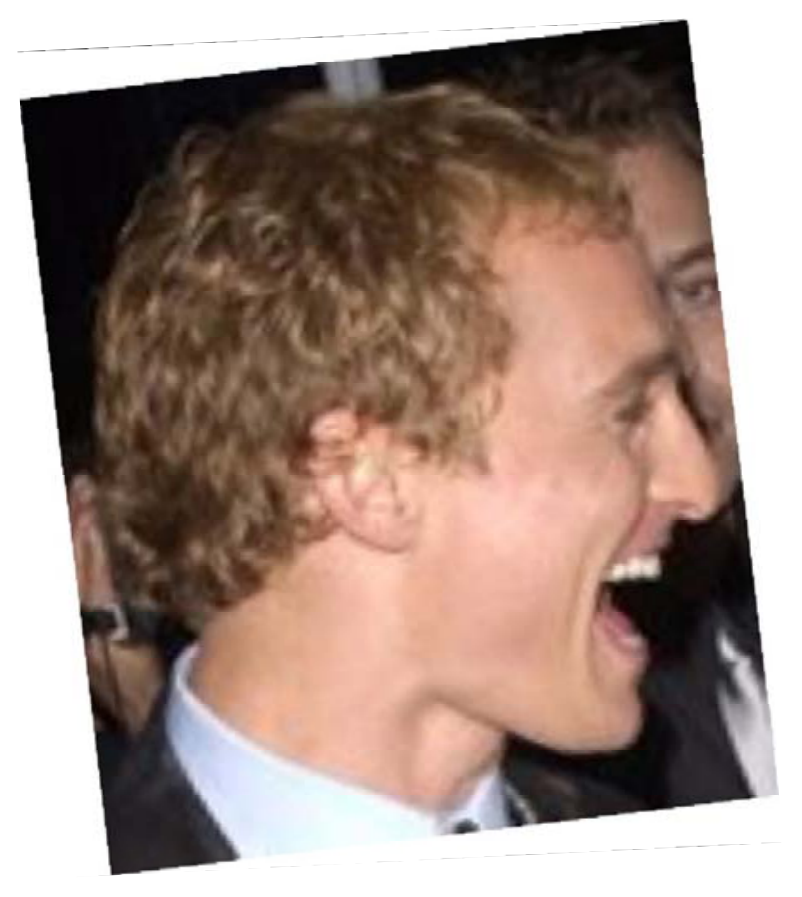




\section{Study sample}

The study sample consisted of ninety seven facial profile photographs from the pretreatment records of a random sample of ninety seven adult white males seeking orthodontic treatment. IRB was obtained from the institutional review board at West Virginia University before the collection of records. The first ninety seven males with a recorded smiling photograph were selected from the active patient files at the West Virginia University School of Dentistry (WVU SOD) orthodontic clinic and from three private orthodontic practices. The inclusion criteria included that pleasing nor unpleasing appearances in profile were not a selection criterion for this sample. Also, no specific skeletal, dental, or facial characteristic were used to select the sample. All images used were of the patients profile with the maxillary central incisors and the forehead fully bared (Figure 7). Exclusion criteria was only if the central incisors or forehead were not fully bared.

Figure 7. Example of an image used in the study sample.

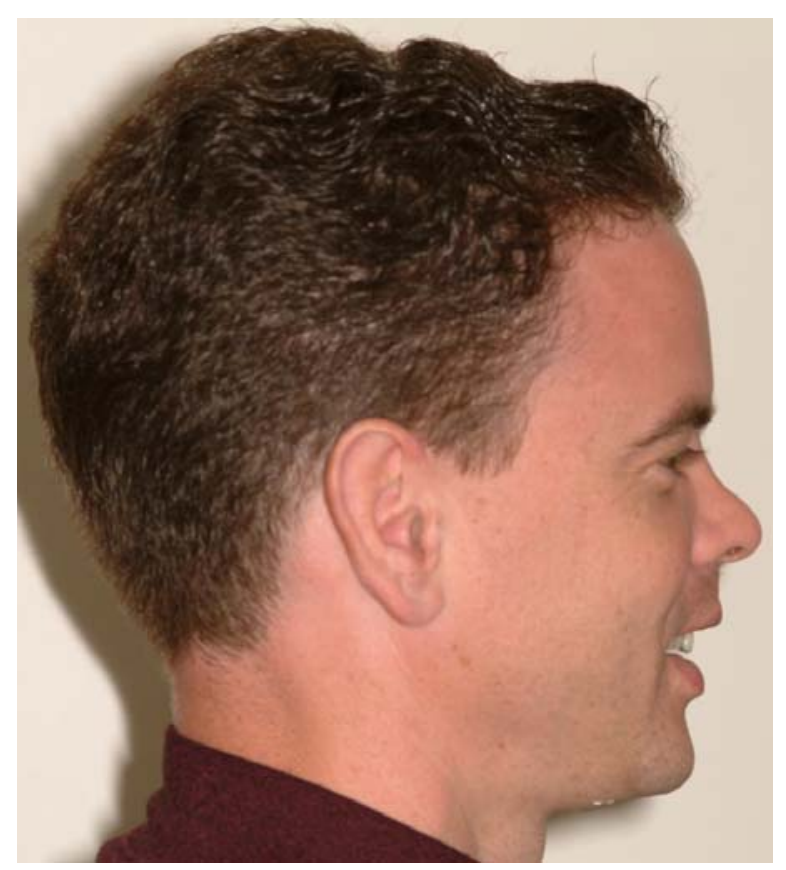




\section{Methodology}

Each photographic image was imported into Adobe Photoshop CS3 ${ }^{\mathrm{TM}}$ file. The images were then resized to approximate life size and rotated to an estimated upright head position. The final upright head position was confirmed by the investigator and one independent practicing orthodontist from the WVU SOD orthodontic clinic. Approximate life size was determined by using the average vertical distance from trichion (hairline) to the incisal edge of the maxillary central incisors measured on the pretreatment lateral cephalograms of a randomly selected sample of ten adult white male patients. The ten cephalograms used were ones that had trichion marked with barium paste prior to taking the head film. The average measurement was $128 \mathrm{~mm}$.

After the images were saved in Adobe Photoshop $\mathrm{CS}^{\mathrm{TM}}$ as approximate life size, all the images were changed to a black and white format. Three independent orthodontists then judged the study sample smiling profile images for whether or not they had good facial harmony. If two of the three orthodontists thought that one of the pictures did not have good facial harmony it was excluded from the study sample. Once the study images were selected, two investigators were asked to determine the natural head position of the images by rotating them in Adobe Photoshop $\mathrm{CS}^{\mathrm{TM}}$. Upon completing this, the images were printed and landmarks and lines were drawn and the images evaluated.

Landmark points for the forehead were identified as described by Andrews ${ }^{5}$ (trichion, superion, glabella, and the FFA point) and marked on each image. The landmark for the maxillary central incisors was the FA point, which is the point on the facial axis that separates the gingival half of the clinical crown from the occlusal half. ${ }^{9}$ Trichion is defined as the hairline and is the most superior aspect of the forehead when the forehead is of relatively flat contour. ${ }^{10}$ 
Glabella is defined as the most inferior aspect of the forehead. ${ }^{10}$ Superion is defined as the most superior aspect of the forehead when the forehead is either rounded or angular in contour. ${ }^{10}$ The FFA point is defined as the midpoint between trichion and glabella for foreheads with flat contour or the midpoint between superion and glabella for foreheads with rounded or angular contour. ${ }^{10}$ All of these points lie on the midsagittal plane of the head. Three vertical reference lines were constructed: line 1 through the forehead's FA point, line 2 through glabella, and line 3 through the maxillary central incisor's FA point. (Figure 8) A fourth reference line (line4) for assessing forehead inclination was constructed by connecting glabella to the uppermost point of the clinical forehead (superion or trichion) as described by Andrews. ${ }^{1}$ (Figure 9) Forehead inclination is described as the angle between line 1 and line 4 .

Figure 8. Forehead landmark points

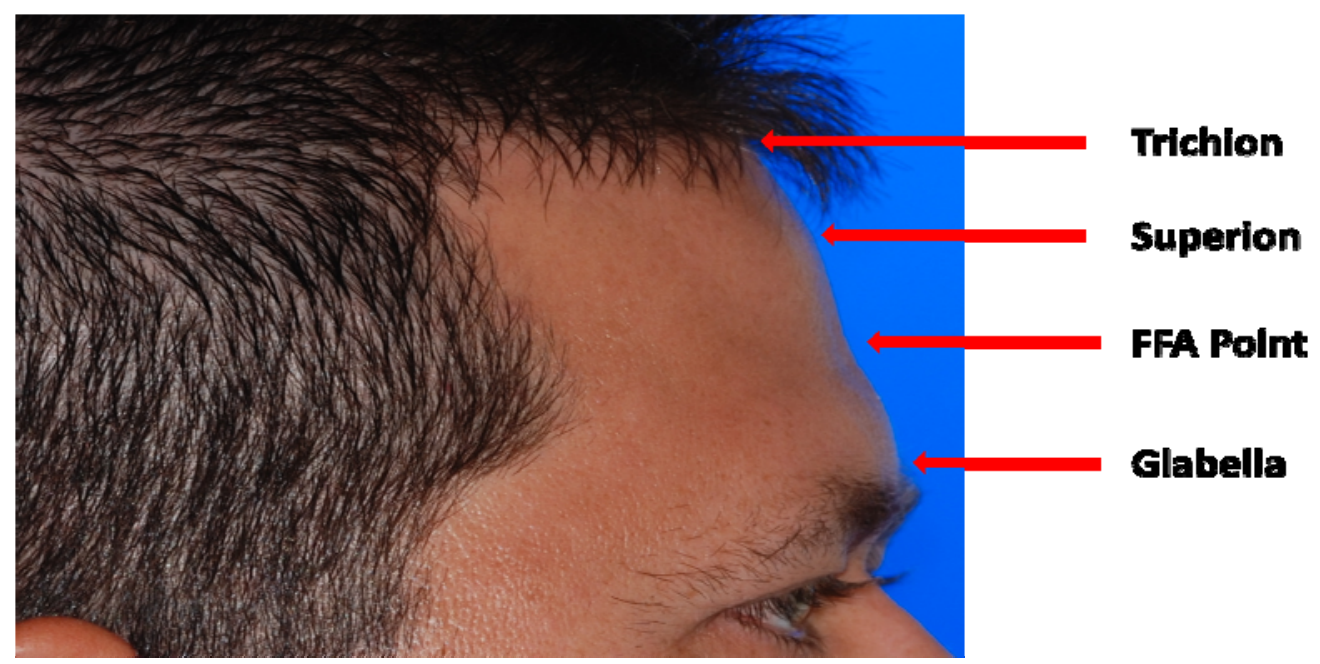


Figure 9. Reference lines used in the study. Line 1 is through the forehead's FFA point. Line 2 is through glabella. Line 3 is through the maxillary central incisor's FA point. Line 4 is through trichion(because it is a straight forehead) and glabella

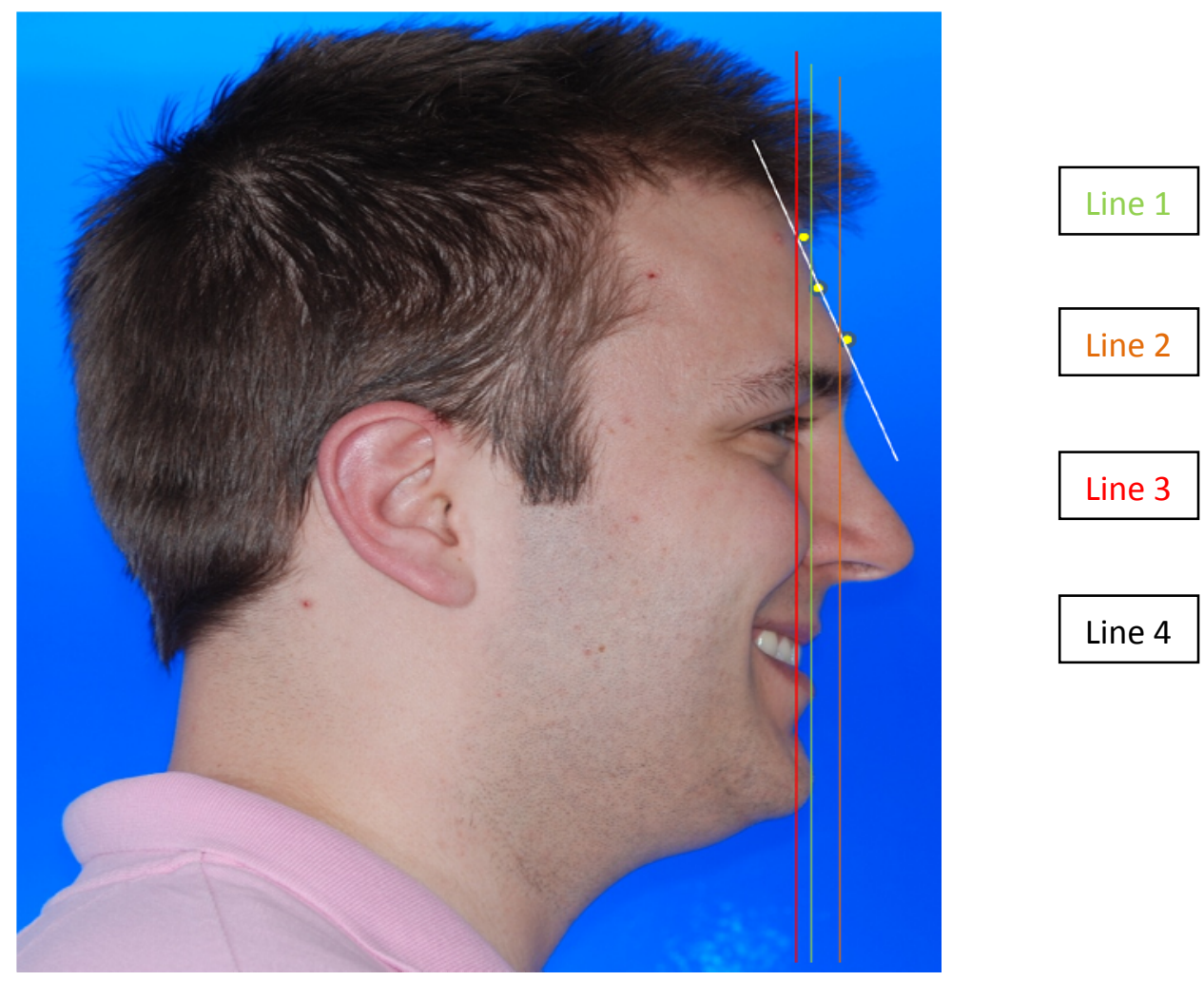

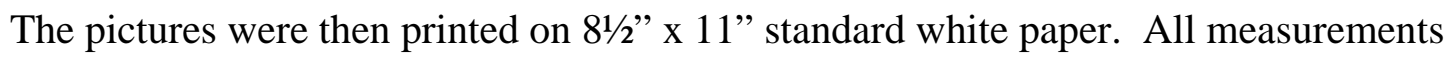
were made on the printed paper by one examiner. The AP relationship of the maxillary central incisors to the forehead was measured as the distance between line 1 and line 3 using a metric ruler to the closest $0.5 \mathrm{~mm}$. A positive value was assigned when the maxillary central incisors (line 3) were anterior to the forehead's FFA point (line 1) and negative when posterior. Forehead inclination was measured as the angle between the line 4 and line 1 using a protractor (Lawrence F. Andrews 1996@) to the closest $0.5^{\circ}$ 


\section{$\underline{\text { Statistical Analysis }}$}

Descriptive and comparative statistical analyses were performed using JVM computer software. The means, standard deviations, and ranges were calculated for maxillary central incisor position relative to the forehead and for forehead inclination in both samples. The means for both samples were compared using a paired two-tailed t-test. A simple second order regression analysis was performed between the maxillary central incisor position and forehead inclination for both samples. Confidence intervals were set at 95\%.

\section{Error Analysis}

All measurements were repeated by the same examiner on a random sample of 10 subjects (5 from the study sample, 5 from the control sample). The systematic error between the first and second measurements was calculated using the Intraclass Correlation Coefficient of Reliability (R). 


\section{CHAPTER 4-RESULTS}

Table 1 and Figures 10 and 11 show the results of the measurement error analysis.

Intraclass Correlation Coefficient of Reliability (R) was used to determine the reliability of the measurements. The $\mathrm{R}$ value ranged from 0 to 1.00 , with $\mathrm{R}$ value greater than 0.90 indicating high reliability.

$$
\mathrm{R}=\frac{(\mathrm{MSA}-\mathrm{MSE})}{\mathrm{MSA}+[(\mathrm{k}-1) \mathrm{MSE}]}
$$

where MSA is the mean square between the variables and $\mathrm{k}$ is the number of repeated measurements.

Table 1. Measurement for Error Analysis

\begin{tabular}{|c|c|c|c|}
\hline & Mean & Standard Deviation & $\mathrm{R}$ \\
\hline Incisor Position & 0.16 & 0.290 & 0.98 \\
\hline Forehead Inclination & 0.2 & 0.317 & 0.98 \\
\hline
\end{tabular}

Figure 10. Measurement of error for AP relationship of the maxillary central incisors (mm).

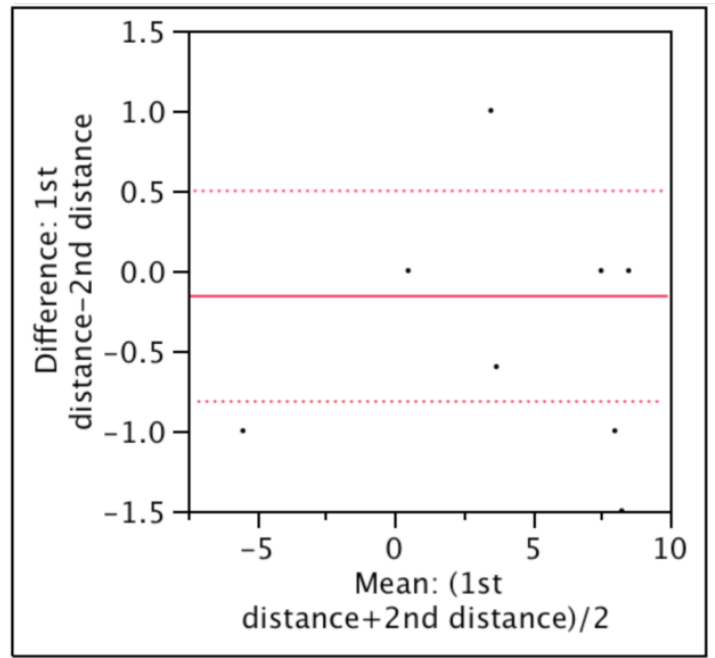


Figure 11. Measurement of error for the forehead inclination (degrees).

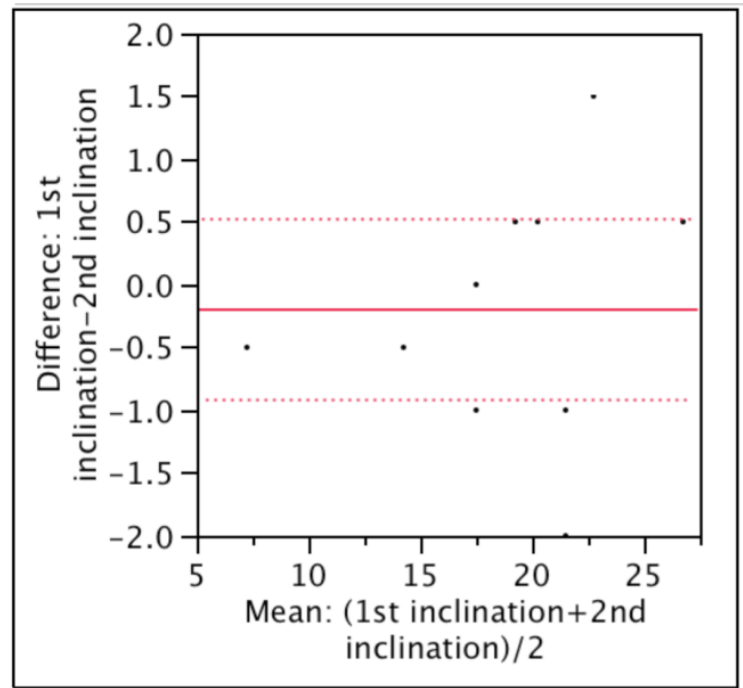

Table 2 and Figure 12 show the AP position of the maxillary central incisors relative to the forehead's FFA point for the control and study samples. For the control sample, the AP position of the maxillary incisors relative to the forehead's FFA point ranged from -6mm to $12 \mathrm{~mm}$, with a mean of $3.22 \mathrm{~mm}$ and standard deviation of $3.17 \mathrm{~mm}$. For the study sample, the AP position of the maxillary central incisors relative to the forehead's FFA point ranged from $24 \mathrm{~mm}$ to $13 \mathrm{~mm}$ with a mean of $-0.31 \mathrm{~mm}$ and a standard deviation of $6.52 \mathrm{~mm}$. The maxillary central incisor position relative to the forehead's FFA point was significantly different between the control sample and the study sample ( $\mathrm{P}=0.0001$; Table 3$)$. 
Table 2. Anteroposterior Position (mm) of the Maxillary Central Incisors Relative to the Forehead's FFA Point (Distance Between Line 1 and Line 3)

\begin{tabular}{|c|c|c|c|c|}
\hline & Mean & SD & Minimum & Maximum \\
\hline Control Sample (n=101) & 3.22 & 3.17 & -6 & 12 \\
\hline Study Sample (n=97) & -0.31 & 6.52 & -24 & 13 \\
\hline
\end{tabular}

Figure 12. Oneway Analysis of Maxiallary Central Incisor Position in the Control and Study Samples

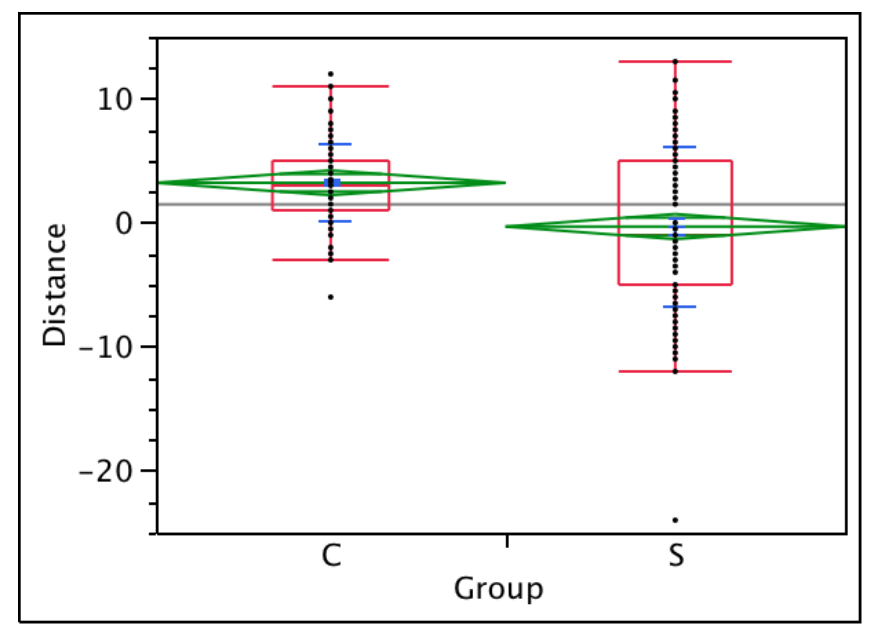

Table 3. Differences in Maxillary Central Incisor Position and Forehead Inclination Between Control and Study Samples

\begin{tabular}{|l|l|l|l|}
\hline & Control & Study & t Ratio \\
\hline Position, mm & 3.22 & -0.31 & -3.53 \\
\hline Forehead inclination, degrees & 19.04 & 17.45 & -1.60 \\
\hline
\end{tabular}


Figures 13 and 14 show where the incisors were located in relationship to the external landmarks. In the control sample, 8 subjects (8\%) had maxillary central incisors positioned posterior to the forehead's FFA point, 1 subject $(<1 \%)$ had maxillary central incisors positioned anterior to glabella, and 92 subjects (91\%) had maxillary central incisors positioned somewhere at or between the FFA point and glabella. In the study sample, 57 subjects (59\%) had maxillary central incisors positioned posterior to the forehead's FFA point. Seven subjects (7\%) had maxillary central incisors positioned anterior to glabella. Thirty three subjects (34\%) had maxillary central incisors positioned somewhere at or between the FFA point and glabella.

Figure 13. Distribution of the anteroposterior maxillary central incisor positions relative to the forehead for the control sample.

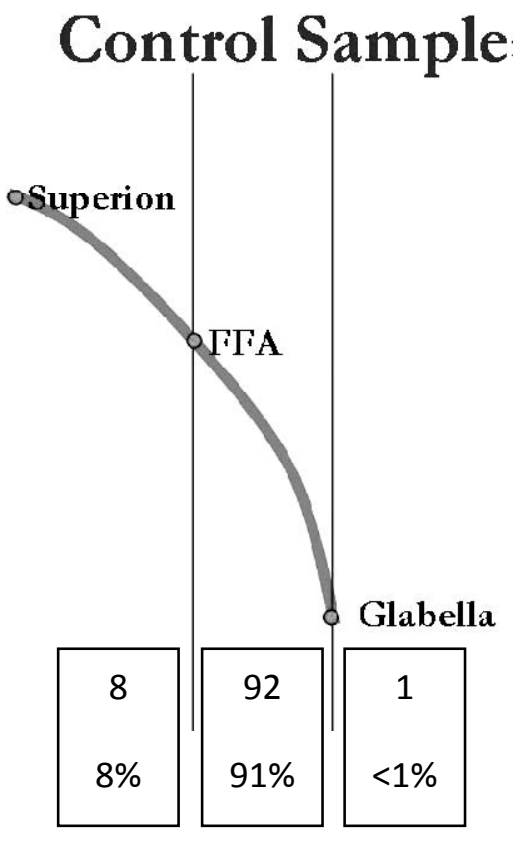


Figure 14. Distribution of the anteroposterior maxillary central incisor positions relative to the forehead for the study sample.

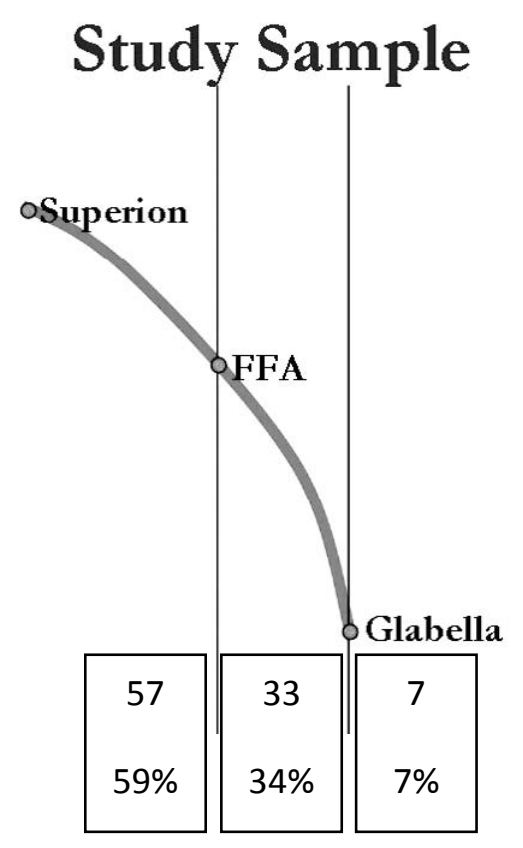

Table 4 shows the forehead inclinations for the control and study samples. For the control sample, the forehead's inclination ranged from $8^{\circ}$ to $30^{\circ}$, with a mean of $19.04^{\circ}$ and standard deviation of $4.58^{\circ}$. For the study sample, the forehead's inclination ranged from $5^{\circ}$ to $29^{\circ}$, with a mean of $17.45^{\circ}$ and standard deviation of $6.09^{\circ}$. Forehead inclination between the control sample and the study sample was significantly different $(\mathrm{P}=0.03$; Table 4).

Table 4. Forehead inclination (Angle between Line 4 and Line 1, in degrees)

\begin{tabular}{|c|c|c|c|c|}
\hline & Mean & SD & Minimum & Maximum \\
\hline Control sample (n=101) & 19.04 & 4.58 & 8 & 30 \\
\hline Study sample (n=97) & 17.45 & 6.09 & 5 & 29 \\
\hline
\end{tabular}


Figures 15 and 16 show the results of the regression analysis between the AP maxillary central incisor position and forehead inclination for both samples. In the control sample the AP positions of the maxillary central incisors were poorly correlated with the inclinations of the forehead $\left(r^{2}=0.37\right)$ and in the study sample they were correlated $\left(r^{2}=0.53\right)$. This study found that for the control group that $16.21^{\circ}$ is the predicted value of the inclination of the forehead when the FFA point and FA point coincide and for the study group $17.71^{\circ}$ is the predicted value of the inclination of the forehead when the FFA point and FA point coincide. So, it can be predicted that in the control group a 1mm increase or decrease in distance between the FFA point and FA point results in a $0.88^{\circ}$ increase or decrease in the inclination of the forehead. For the study group it can be predicted that a 1mm increase or decrease in the distance between the FFA point and FA point results in a 0.68 degrees increase or decrease in the inclination of the forehead.

Figure 15. Change in anteroposterior maxillary central incisor position vs. change in forehead inclination for the control sample, $\mathrm{r}^{2}=0.37$

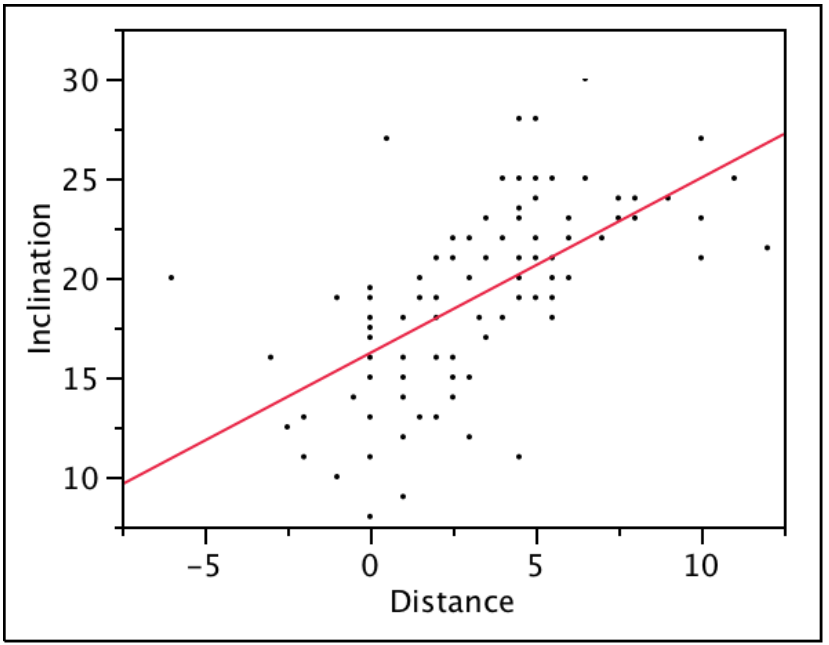


Figure 16. Change in the anteroposterior maxillary central incisor position vs. change in forehead inclination for the study sample, $\mathrm{r}^{2}=0.53$

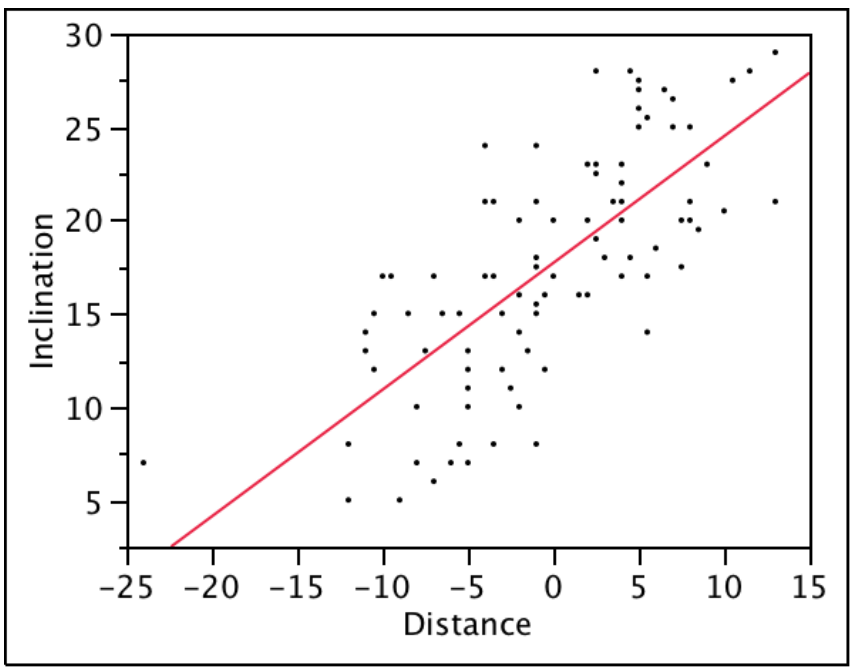




\section{CHAPTER 5-DISCUSSION}

The AP position of the maxillary central incisors can be evaluated clinically using the forehead as reference. This study showed how the FFA point can be used as a landmark on the soft tissue forehead to evaluate the AP position of the maxillary central incisors.

The AP position of the maxillary central incisors between the control and study groups was found to be statistically significant. On average the FA point of the maxillary central incisors in the control group were located $3.22 \mathrm{~mm}$ ahead of the FFA point, whereas, in the study group the FA point was located on average $0.31 \mathrm{~mm}$ behind the FFA point. This indicates that the male subjects considered to be "good looking” had maxillary central incisors positioned not just more anteriorly than the study group, but also in front of the FFA point by a significant amount. This is in agreement with the results reported by Andrews on the white females. In Andrews study on average the FA point of the maxillary central incisors in the control group were located 2.5mm ahead of the FAA point, whereas, in the study group the FA point was located on average $1.2 \mathrm{~mm}$ behind the FFA point.

According to Andrews' study on adult white females, he found that treatment goals for adult white females should include the condition that the maxillary central incisors be positioned somewhere at or between the forehead's FA point and glabella. ${ }^{10}$ This study confirms that this also holds true for adult white males as 92 subjects(91\%) in the control group had maxillary central incisors with FA points located between the FFA point and glabella whereas, only 33subjects (34\%) had maxillary central incisors with the FA points located between the FFA point and glabella. So, it is obvious that a greater percentage of the control group had incisors 
located between the FFA point and glabella, thus confirming that this agrees with Dr. Andrew's study.

Forehead inclination in this study was found to be statistically significant between the control and study groups as in Andrews' study on adult white females. However, unlike his study where the AP position of the maxillary central incisors were strongly correlated $\left(r^{2}=0.64\right)$ with forehead inclination in his control group, this study showed minimal correlation between AP position of maxillary central incisors and forehead inclination $\left(r^{2}=0.37\right)$ and greater correlation for the study group $\left(\mathrm{r}^{2}=0.53\right)$. The fact that the forehead inclination is not highly correlated with the AP maxillary incisor position could be due to a number of possibilities. It could possibly be due to greater variations in the inclinations and amount frontal bossing seen in a male (which is not seen in females). Another possibility is that glabella tends to be located more anterior in men. ${ }^{54}$ Lastly, it could simply be due to the limitations of the study which include that personal preferences for characteristics contributing to facial beauty and harmony may be biased by the mass media's selection of adult white male models for their publications and approximating the control sample photographs to life size can introduce some variability. 


\section{CHAPTER 6-SUMMARY AND CONCLUSIONS}

\section{Summary}

The purpose of this study was to evaluate and compare the anteroposterior relationship of the maxillary central incisors to the forehead in adult white males with harmonious profiles (control sample) with a random sample of adult white males seeking orthodontic treatment. (study sample).

The control sample consisted of one hundred and one facial photographic images of adult white males in smiling profile collected from various internet website publications including many magazine websites. The criteria for inclusion were as follows 1) the maxillary central incisors will be fully bared and 2) the subjects have a generally pleasing appearance in profile (Figure 6). A panel of three orthodontists examined the photographs and determined whether the profile was pleasing. Two of the three of the evaluators had to agree that the profile was pleasing in order for it to be included, if not these photographs were excluded from the study.

The study sample consisted of ninety seven facial profile photographs from the pretreatment records of a random sample of ninety seven adult white males seeking orthodontic treatment. IRB was obtained from the institutional review board at West Virginia University before the collection of records. The first ninety seven males with a recorded smiling photograph were selected in alphabetical order from the active patient files at the West Virginia University School of Dentistry (WVU SOD) orthodontic clinic and three private orthodontic practices. Pleasing nor unpleasing appearances in profile were not a selection criterion for this sample. Also, no specific skeletal, dental, or facial characteristic were used to select the sample. 
All images used were of the patients profile with the maxillary central incisors and the forehead fully bared (Figure 7).

The AP relationship of the maxillary incisors to the forehead were evaluated as described by Andrews. ${ }^{10}$ Analysis of variance (ANOVA) was used to compare the AP relationship of the incisors relative to the external forehead landmarks (millimeters) and the forehead inclination (degrees). For the AP relationship the means were statistically significant $(\mathrm{P}=0.0001)$ and for forehead inclination the means were significantly different $(\mathrm{P}=0.03)$. A regression analysis was used to study the relationship between the AP relationship of the maxillary central incisors and the forehead inclination. This study found that there was a statistically significant difference between the control and study groups, but that the correlation of the AP position of the maxillary

central incisors was higher for the study group than the control group $\left(\mathrm{r}^{2}=0.53\right.$ and $\mathrm{r}^{2}=0.37$, respectively).

\section{Conclusions}

The first hypothesis (1) There is no significant difference in the position of the maxillary central incisors with reference to the forehead's FFA point between white male patients seeking orthodontic treatment compared to a control group of adult white male subjects with harmonious facial profiles was rejected. And the second hypothesis (2) There is no significant difference in the correlation of the maxillary central incisors with the inclination of the forehead between adult white male patients seeking orthodontic treatment compared to a control group of white male subjects with harmonious facial profiles was also rejected. 


\section{CHAPTER7- RECOMMENDATIONS FOR FUTURE RESEARCH}

1. A new study group could be obtained that more closely resembles the study group of Dr. Will Andrews, because this study group included some "famous” people that could have potentially biased the panel judges into saying that they had good facial harmony when they didn’t.

2. A larger sample size would better represent the control and study groups.

3. Additional studies need to be done on subjects of different racial/ethnic groups.

4. Additional studies need to be done on subjects of different ages. 


\section{Reference List}

1. Arnett GW, Bunson MJ \& McLaughlin RP. The essence of beauty. 2002. Ref Type: Unpublished Work

2. Berschield E \& Gangestad S The social psychological implications of physical attractivness. Clin Plast Surg 9, 289-296 (1982).

3. Giddon DB Orthodontic applications of psychological and perceptual studies of facial esthetics. Semin Orthod 1, 82-93 (1995).

4. Arnett GW \& Bergman RT Facial keys to orthodontic diagnosis and treatment planningPart I. Am J Orthod Dentofacial Orthop. 103, 299-312 (1993).

5. Michiels LYF \& Tourne LPM Nasion true vertical: a proposed method for testing the clinical validity of cephalometric measurements applied to a new cephalometric reference line. Int J Adult Orthod Orthog Surg 5, 43-52 (1990).

6. Andrews, L. \& Andrews WA Syllabus of the Andrews' Orthodontic Philosophy. San Diego (1999).

7. Richardson A An investigation into the reproducibility of some points, planes, and lines used in cephalometric analysis. Am J Orthod. 52, 637-651 (1966).

8. Phillips C, Bennett ME \& Broder HL Dentofacial disharmony: psychological status of patients seeking treatment consultation. J Appl Psychol 68, 556 (1998).

9. Schlosser JB, Preston CB \& Lampasso J The effects of computer-aided anteroposterior maxillary incisor movement on rating of facial attractiveness. Am J Orthod Dentofacial Orthop. 127, 17-24 (2005).

10. Andrews, W. AP relationship of the maxillary central incisors to the forehead in adult white females. Angle Orthod. 78, 662-669 (2008).

11. Anic-Milosevic S, Lapter-Varga M \& Slaj M Analysis of soft tissue facial profile by means of angular measurements. European J Orthod. 30, 135-140 (2008).

12. Park YC \& Burstone CJ Soft tissue profile---falacies of hard tissue standards in treatment planning. Am J Orthod Dentofacial Orthop. 90, 52-62 (1986).

13. Bishara SE Textbook of Orthodontics. W.B. Saunders Co., Philadelphia (2001).

14. McLaughlin RP \& Bennett JC Orthodontic management of the dentition with the preadjusted appliance. Iris Medical Media Ltd., Oxford (1997).

15. Proffit WR \& Fields HW Contemporary Orthodontics. Mosby, St. Louis (2000). 
16. Andrews, L. F. Straight Wire: The Concept and Appliance. L.A. Wells Co., (1989).

17. Arnett, G. W. \& Gunson, M. J. Facial planning for orthodontists and oral surgeons. Am. J Orthod. Dentofacial Orthop. 126, 290-295 (2004).

18. Andrews, L. F. Six elements orthodontics. Andrews J Orthod and Orofac Harmony 1(1). 2000.

Ref Type: Journal (Full)

19. Andrews, L. F. Syllabus of philosophy and techniques. 2001.

Ref Type: Conference Proceeding

20. Burstone CJ The integumental profile. Am J Orthod. 44, 1-25 (1958).

21. Alley TR \& Heldebrand Appearance and esthetics I oral health. Community Dentistry and Oral Epidemiology 8, 244-256 (1980).

22. Dion KK, Berschield E \& Walster E What is beautiful is good. J Pers Soc Psychol 24, 285-290 (1972).

23. Mantzikos T Esthetic soft tissue profile preferences among the Japanese population. Am J Orthod Dentofacial Orthop. 114, 1-7 (1998).

24. Polk MS et al. Soft tissue profile: a survey of African AMerican preferences. Am $J$ Orthod Dentofacial Orthop. 108, 90-101 (1995).

25. Xu Tian-Min et al. Facial attractiveness: Ranking of end-of-treatment facial photographs by pairs of Chinese and US orthodontists. Am J Orthod Dentofacial Orthop. 134, 74-84 (2008).

26. Herz-Fischler R A mathematical history of the golden number. Dover Publications, New York (1998).

27. Moss JP, Linney AD \& Lowry MN The use of three-dimensional techniques in facial esthetics. Semin Orthod 1, 94-104 (1995).

28. Baker BW \& Woods MG The role of the divine proportion in the esthetic impprovement of patients undergoing combined orthodontic/orthognathic surgical treatment. Int J Adult Orthod Orthog Surg 16, 108-120 (2001).

29. Ricketts RM The biologic significance of the divine proportion and Fibonacci series. Am J Orthod. 81, 351-370 (1982).

30. Adams TB Optimal dental and facial esthetics in orthodontics--a multifaceted challenge. Tex Dent J 119, 1019-1031 (2002). 
31. Ackerman JL, Proffit WR \& Sarver DM The emerging soft tissue paradigm in orthodontic diagnosis and treatment plannig. Clinical Orthodontic Research 2, 49-52 (1999).

32. Proffit WR The soft tissue paradigm in orthodontic diagnosis and treatment planning: a new view for a new century. J Esthet Dent 12, 46-49 (2000).

33. Ricketts RM Perspectives in the clinical application of cephalometrics. Angle Orthod. 51, 115 (1981).

34. Downs WB Analysis of the dentofacial profile. Angle Orthod. 26, 191-212 (1956).

35. Steiner CC Cephalometrics for you and me. Am J Orthod. 39, 729 (1953).

36. Jacobson A The 'Wits' appraisal of jaw harmony. Am J Orthod. 1975, 125-138 (1975).

37. Tweed CH Clinical Orthodontics., pp. 6-60 (Mosby, St. Louis,1966).

38. Baumrind S \& Frantz RC The reliability of head film measurements. 1. Landmark idenification. Am J Orthod. 60, 111-127 (1971).

39. Wylie GA, Fish LC \& Epker BN Cephalometrics: a comparison of five analyses currently used in the diagnosis of dentofacial deformities. Int J Adult Orthod Orthog Surg 2, 15-36 (1987).

40. Angle EH Malocclusion of the teeth. S. S. White Dental Manufacturing Company, Philadelphia (1907).

41. Kuyl MH, Verbeek RMH \& Dermaut LR The integumental profile: a reflection of the underlying skeletal configuration? Am J Orthod Dentofacial Orthop. 106, 597-604 (1994).

42. Ricketts RM Planning treatment on the basis of the facial pattern and an estimate of its growth. Angle Orthod. 27, 14-37 (1957).

43. Satravaha S \& Schlegel KD The significance of the integumentary profile. Am J Orthod Dentofacial Orthop. 1987, 422-426 (1987).

44. Hinds EC \& Kent JN Surgical treatment of developmental jaw deformities. The CV Mosby Company, St. Louis (1972).

45. Burstone CJ Lip posture and its significance in treatment planning. Am J Orthod. 53, 262-284 (1967).

46. Legan HL \& Burstone CJ Soft tissue cephalometric analysis for orthognathic surgery. Am J Orthod. 38, 744-751 (1980).

47. Holdaway RA. A soft-tissue cephalometric analysis and its use in orthodontic treatment planning. Part I. Am J Orthod. 84, 1-28 (1983). 
48. Bass, N. The esthetic analysis of the face. European J Orthod. 13, 343-350 (1991).

49. Merrifield LL The profile line as an aid in critically evaluating facial esthetics. Am $J$ Orthod. 52, 804-822 (1966).

50. Powell N \& Humphreys B Proportions of the esthetic face. Thieme-Stratten, New York (1984).

51. Epker BN Esthetics and treatment of facial form., pp. 187-216 Ann Arbor: Center for Human Growth and Development,1992).

52. Andrews, L. Six elements orthodontics. Andrews J Orthod and Orofac Harmony 1(1). 2000.

Ref Type: Journal (Full)

53. Andrews, L. Straight Wire: The Concept and Appliance. L.A. Wells Co., (1989).

54. Lee MK, Sakai O, Spiegel JH. CT measurement of the frontal sinus-gender differences and implications for frontal cranioplasty. J Craniomaxillofac Surg 38, 494-500 (2010). 